\title{
Non-Uniform Synergistic Effect of Sn and Ru in Site-Specific Catalytic Activity of Pt at Bimetallic Surfaces toward CO Electro-oxidation
}

\author{
Manuel J. S. Farias* ${ }^{* \dagger}$, William Cheuquepán ${ }^{\ddagger}$, Auro A. Tanaka ${ }^{\dagger}$, Juan M. Feliu ${ }^{\ddagger}$ \\ †Departamento de Química, Universidade Federal do Maranhão, Avenida dos \\ Portugueses, 1966 - CEP 65080-805, São Luís (MA), Brazil \\ \$nstituto de Electroquímica, Universidad de Alicante Ap. 99, E-03080, Alicante, Spain
}

\begin{abstract}
This work investigates the mechanisms by which $\mathrm{Sn}$ and $\mathrm{Ru}$ can improve or inhibit the site-specific catalytic activity of $\mathrm{Pt}$ (neighboring or distant from foreign atoms) at bimetallic surfaces. For this purpose, we decorated Pt stepped surfaces (non-equivalent sites) by site-selective electrodeposition of different coverages of either Sn or Ru on (110) Pt steps, forming $\mathrm{Sn}_{\text {steps }} / \mathrm{Pt}(h k l)$ and $\mathrm{Ru}_{\text {steps }} / \mathrm{Pt}(h k l)$ bimetallic surfaces, and we used $\mathrm{CO}$ adlayer electro-oxidation as a surface probe reaction, monitored by in situ FTIR and cyclic voltammetry techniques. The results showed that both $\mathrm{Sn}$ and $\mathrm{Ru}$ selectively accelerated the reaction pathway of CO electro-oxidation only at the (111) Pt terrace sites, but importantly played different underlying roles in favoring activity at these active sites. In case of $\mathrm{Sn}_{\text {steps }} / \mathrm{Pt}(h k l)$ catalysts, the $\mathrm{CO}$ adlayer oxidation started at lower potentials than on $\mathrm{Ru}_{\text {steps }} / \mathrm{Pt}(h k l)$, but Sn only improved the activity at sites on atoms of the first rows of (111) Pt terraces, while the catalytic benefit of $\mathrm{Ru}$ seemed to extend further along the (111) Pt terraces. Compared to unmodified Pt surfaces, Ru did not influence the activity at the line of the (110) Pt steps, while Sn slightly inhibited the activity there, which characterized a slight contrasting effect in catalytic activity at the (111) terraces compared to the (110) step sites. In this regard, the chemical modification by irreversible deposition of either $\mathrm{Sn}$ or $\mathrm{Ru}$ at lines of Pt steps on a stepped Pt surface interestingly resulted in a non-uniform synergistic effect or balancing of energies involving different site-specific catalytic activities at non-equivalent Pt surface sites. Since the electro-oxidation of CO takes place at the (111) Pt terrace sites away from $\mathrm{Sn}$ or $\mathrm{Ru}$, and because $\mathrm{CO}_{\text {ads }}$ behaves as an immobile species during its oxidation, it is reasonable to assume that the classical bifunctional mechanism completely fails as a model to interpret the enhancement of catalytic activity towards $\mathrm{CO}$ electro-oxidation at $\mathrm{Sn}_{\text {steps }} / \mathrm{Pt}(h k l)$ or $\mathrm{Ru}_{\text {steps }} / \mathrm{Pt}(h k l)$
\end{abstract}


catalysts. The selective alteration in site-specific catalytic activity of Pt was related to: $(i)$ the type and coverage of foreign atoms ( $\mathrm{Sn}$ or $\mathrm{Ru}$ ) at the lines of Pt steps; (ii) the crystallographic orientation of Pt sites, whether (111) terraces or steps; and (iii) the width of the (111) Pt terraces.

Keywords: bimetallic surfaces; electrocatalysis; surface structure sensitivity; CO electrooxidation; Langmuir-Hinshelwood mechanism; bifunctional mechanism.

*Author to whom correspondence should be addressed: manueljsfarias@gmail.com (M.J.S. Farias); Phone: +55 9833018246. 


\section{Introduction}

In heterogeneous (electro)catalysis, successful tailoring of the catalytic performance of solid catalysts can be achieved based on synergistic effects created when a host catalyst material is modified by the addition of a foreign catalyst component. ${ }^{1-3}$ When a mother (or host) catalyst is modified, this can result in greater catalytic activity (towards a specific reaction), as well as higher selectivity and improved stability, compared to the original material alone. ${ }^{4}$ In this regard, well-characterized Pt provides a good model surface for fundamental electrocatalytic studies. This surface can be modified by depositing a layer (or sub-layer) of foreign catalyst components (such as $\mathrm{Sn}$ or $\mathrm{Ru})^{5}$, in order to tailor its catalytic performance as an anode in the oxidation of hydrogen (and alcohol) in low temperature fuel cells. In fact, Pt-Sn and Pt-Ru are state-of-the-art catalysts that offer greatly improved efficiency and prevention against the poisoning action of $\mathrm{CO}$, which when present in even small amounts (ppm) can drastically decrease the kinetics of oxidation of hydrogen gas. ${ }^{6,7}$ However, the engineering involved in the modification of a solid catalyst surface in order to tune its catalytic performance is not trivial. The main reason is the highly complex nature of a solid catalyst surface, as revealed by the diversity of active sites with different chemical environments, which is intrinsic to the catalyst surface. ${ }^{8}$ The alteration of a Pt surface possessing non-equivalent active sites by the deposition of a layer of a foreign catalyst component (such as Sn or $\mathrm{Ru}$ ) implies rebalancing, in terms of both magnitude and behavior, of the catalytic performance of different active sites at the Pt surface. This is an elegant problem in heterogeneous electro(catalysis), considering the ways that the catalytic performance of different Pt surface sites can be tailored by the presence of foreign catalyst components. One of the most important tasks in heterogeneous (electro)catalysis research is to understand the origin of the dependence of the rate of reaction upon the catalyst surface structure, which includes the arrangement of atoms at the surface (and subsurface) and the chemical composition. ${ }^{8}$

The catalytic benefits towards CO (electro)oxidation of the addition of either Sn or $\mathrm{Ru}$ to Pt have generally been interpreted in terms of ( $\mathrm{i}$ ) ligand/electronic effects, ${ }^{9-11}$ (ii) strain effects, ${ }^{12}$ and (iii) the so-called bifunctional mechanism. ${ }^{13-16}$

In the case of ligand/electronic effects, the electronic state of the $d$ band of $\mathrm{Pt}$ is modified by the foreign metal, which can affect the energies of catalyst-adsorbate interactions. ${ }^{17,18}$ The electronic effect in heterogeneous (electro)catalysis can be understood as a condition in which modifying atoms form a subsurface (or near-surface) 
alloy, ${ }^{19}$ where there is no direct contact between the heteroatoms and the species involved in any step of the catalyzed reaction occurring at the catalyst surface. Similarly, on a perfect Pt-based core-shell structure, all the steps of the catalyzed reaction occur only at the Pt domains, despite the predominance of a surface lattice strain effect in this case. ${ }^{20,21}$ There is another situation in which foreign catalyst components, even when located at the catalyst surface, may not directly catalyze any of the steps of the overall reaction pathway, while their presence at the surface may influence steps of the catalyzed reaction occurring distant from them at the surface. ${ }^{9}$ In the case of the strain effect, the presence of a foreign catalyst component results in the search for a new lattice position, due to the effect on the average metal-metal bond length. ${ }^{22}$ However, in the case of the electro-oxidation of $\mathrm{CO}$, it is not clear why one strained catalyst material may be beneficial for the reaction, while another has a deleterious effect. ${ }^{21,23}$

In the bifunctional mechanism, ${ }^{13,14,24-26}$ the main concept is that sites at the second catalyst component, adjacent to the host metal sites, act cooperatively with the latter, coupling their different functions for elementary steps of a catalyzed reaction, which may (but not necessarily) converge towards the same overall reaction pathway on the catalyst surface. In the case of CO electro-oxidation, it is claimed that those sites at Pt domains are responsible for the adsorption of $\mathrm{CO}$, while foreign components, which have more pronounced oxophilic character than the Pt sites, are responsible for the water activation (dissociation) step $-\mathrm{H}_{2} \mathrm{O}+\mathrm{Y}_{\alpha \text {-active site }} \rightleftarrows \mathrm{Y}_{\alpha^{-}}(\mathrm{OH})+\mathrm{H}^{+}+e^{-}-$at a lower threshold potential than at Pt sites. According to the bifunctional mechanism, it is claimed that the metallic Pt-based interphase contains the most active sites for conversion of $\mathrm{CO}$ to $\mathrm{CO}_{2}$ at lowest overpotentials, ${ }^{26-29}$ while Pt sites distant from the foreign component have lower catalytic activity. ${ }^{28-30}$ Moreover, if $\mathrm{Pt}$ sites are distant from foreign catalyst components, the action of the bifunctional mechanism requires that in $\mathrm{CO}$ stripping experiments, the $\mathrm{CO}_{\mathrm{ads}}$ reactants on bimetallic surfaces must diffuse from Pt sites (domains such as Pt islands) to intermetallic Pt-based interfaces. In this case, it is generally claimed that adsorbed CO is a mobile species on the catalyst surface, ${ }^{31}$ which is a hypothesis that can be tested by means of CO stripping experiments. An additional issue in the case of the bifunctional mechanism concerns the capacity for nucleation of oxygen-containing species on a highly oxophilic foreign catalyst component, although this does not seem to be a sufficient prerequisite for catalytic promotion, because the electro-oxidation of $\mathrm{CO}$ has not been found to be improved on $\mathrm{CeO}_{2}$-modified Pt electrodes. ${ }^{32}$ Moreover, it is commonly believed that catalytic promotion involves all these effects acting together to greater or 
lesser extents, ${ }^{33}$ which in principle provides an overall improvement in the catalytic activity of active sites at a bimetallic surface as a whole, although this issue still requires further elucidation.

Investigation of the $\mathrm{CO}$ electro-oxidation reaction in acid solution using $\mathrm{Pt}-\mathrm{Ru}$ alloys of different compositions showed highest activity for a 1:1 ratio of $\mathrm{Ru}$ and $\mathrm{Pt},{ }^{34,35}$ suggesting that catalytic activity was maximized according to the number of pairs of $\mathrm{Pt}$ and $\mathrm{Ru}$ sites at the catalyst surface. However, Gasteiger et al. ${ }^{34}$ and Lin et al. ${ }^{35}$ reported voltammetric profiles tailing towards high potentials, indicating that a portion of the $\mathrm{CO}$ layer had continued to be electro-oxidized at potentials above $\sim 0.6 \mathrm{~V}_{\mathrm{RHE}}$, similar to the potential at which electro-oxidation at Pt occurred. Similarly, data presented by Hayden et $a l .{ }^{36}$ for $\mathrm{CO}$ electro-oxidation at a Pt-Sn alloy also showed that the onset potential for reaction was significantly lowered (compared to $\mathrm{Pt}$ ), while a significant portion of $\mathrm{CO}_{\mathrm{ads}}$ was only oxidized at potentials similar to $\mathrm{Pt}$, as also observed by Massong et al. ${ }^{37}$ for a Sn-modified Pt(332) and Rizo et al. ${ }^{38}$ for a Sn-modified Pt(111) electrodes. For all the catalysts above (bimetallic Pt-Sn and Pt-Ru), the improvement in electrocatalysis of $\mathrm{CO}$ oxidation was interpreted in terms of a prevalent bifunctional mechanism. ${ }^{34,36,38}$ Stamenković et al..$^{39}$ used a $\operatorname{Pt}(111) / \operatorname{Sn}(2 \times 2)$ alloy surface with $\theta_{\mathrm{Sn}}=0.25$ and proposed that high activity at low potentials $\left(\sim 0.2 \mathrm{~V}_{\mathrm{RHE}}\right)$ was probably related to the existence of weakly adsorbed $\mathrm{CO}$ adjacent to $\mathrm{OH}_{\text {ads }}$-covered $\mathrm{Sn}$ atoms, with this $\mathrm{CO}_{\text {ads }}$ being oxidized first on the surface (irrespective of whether $\mathrm{CO}_{\mathrm{ads}}$ was present at either step or terrace sites). The $\mathrm{Sn}$ and $\mathrm{Ru}$ in bulk structures present significant chemical differences in terms of their affinity to bind with $\mathrm{CO}$, which is negligible in the case of $\mathrm{Sn},{ }^{37,40}$ while CO can strongly adsorb on bulk Ru. ${ }^{9}$ However, it is evident that water can adsorb on both $\mathrm{Sn}$ and $\mathrm{Ru}$. Based on these similarities and differences, it has been suggested that it is only on a Pt-Sn surface that CO electro-oxidation proceeds according to a "pure" bifunctional mechanism. ${ }^{24}$ The mechanisms by which $\mathrm{Sn}$ and $\mathrm{Ru}$ alter the catalytic properties of $\mathrm{Pt}$ have been associated with different states of adsorbed CO on Pt-Sn and Pt-Ru alloys. ${ }^{40}$

Actually, the mechanisms involved in the catalytic improvement of Pt by $\mathrm{Sn}$ or $\mathrm{Ru}$ towards the $\mathrm{CO}$ electro-oxidation reaction are more complex than currently believed. In this sense, it is necessary to improve understanding of the causes of high catalytic activity of such Pt-based catalysts and the way that the foreign catalyst component affects the catalytic activity of $\mathrm{Pt}$ sites. This can be achieved by depositing a sub-layer of a foreign catalyst component at selected sites of a Pt stepped surface, followed by investigation of the catalytic properties of this type of catalyst surface. In our earlier work, an investigation 
was made of the mechanism by which Ru adjusted the catalytic activities of Pt terrace and low-coordinated sites, ${ }^{41}$ with the results indicating that the reasons for improved catalytic activity of the Pt-based catalysis were more complex than previously believed.

The aim of the present study was to improve understanding of the nature and properties of the active sites involved in CO electro-oxidation at highly active Pt-based catalysts. Investigation was made of the synergism between different Pt and foreign metal ( $\mathrm{Sn}$ or $\mathrm{Ru})$ sites at $\mathrm{Sn}_{\text {steps }} / \mathrm{Pt}(h k l)$ and $\mathrm{Ru}_{\text {steps }} / \mathrm{Pt}(h k l)$ hetero-bimetallic surfaces. Additionally, comparison was made of the roles played by $\mathrm{Sn}$ and $\mathrm{Ru}$ in site-specific synergistic effects with Pt. The approach used to elucidate these systems employed cyclic voltammetry and in situ FTIR techniques.

\section{Experimental Section}

Two bead-type well-oriented stepped Pt single crystals were employed as working electrodes, having $\operatorname{Pt}(554)$ and $\operatorname{Pt}(332)$ Miller indices and oriented areas of $\sim 4.7$ and $\sim 4.3$ $\mathrm{mm}^{2}$, respectively. These oriented surfaces were characterized by (111) terraces of $n$ atoms width (9 and 5 for $\operatorname{Pt}(554)$ and $\operatorname{Pt}(332)$, respectively), periodically interrupted by monoatomic steps with (110) orientation. The surfaces therefore contained crystalline imperfections in the form of (110) steps within the $x-y$ plane with (111) orientation. These types of stepped surfaces can be obtained by cutting the crystal at a small angle of $\tan ^{-1}\left(\frac{2 \sqrt{2}}{3 n-2}\right)$ away from the (111) plane, along the zone line of the steps with (110) orientation. $^{42}$ According to the Lang-Joyner-Somorjai ${ }^{43}$ (LJS) model, these stepped surfaces have a surface configuration denoted as $\operatorname{Pt}(\mathrm{s})-[(n-1)(111) \times(110)]$, with Miller index of $(n, n, n-2)$. Figure 1 shows a hard sphere model of an fcc (332) stepped surface, identifying sites including the (110) steps (or the steps with (111) configuration) and the (111) terraces. As shown in Figure 1, the steps involve a local combination or junction between two Miller indices, with the steps ending at the final or penultimate row of atoms at the (111) terraces. This can be seen in Figure 1, where the block of atoms marked as 1, 2, 3, and 4 illustrates the (110) steps (a square type configuration), and 1', 2', and 3' indicate the (111) step orientation (a triangular type configuration). This figure also illustrates the (111) terraces plane. It is important to highlight that the representation of the steps as being (110) orientation is significant from the electrochemical point of view, because the blank voltammetry of Pt (as shown in Figure 2) showed a reversible feature in the hydrogen region. This could be ascribed to adsorption/desorption of hydrogen at 
the top of the steps (indicated in Figure 1), with all the other sites at the Pt surface behaving as terrace sites. ${ }^{44,45}$

According to the LJS model, ${ }^{43}$ the $\mathrm{Pt}(554)$ and $\mathrm{Pt}(332)$ surfaces can individually be represented as:

$$
\begin{gathered}
\operatorname{Pt}(s)-[9(111) \times(110)] \equiv \operatorname{Pt}(554) \text { or } \operatorname{Pt}(s)-[10(111) \times(111)] \\
\text { and } \\
\operatorname{Pt}(s)-[5(111) \times(110)] \equiv \operatorname{Pt}(332) \text { or } \operatorname{Pt}(s)-[6(111) \times(111)] .
\end{gathered}
$$

The stepped Pt single crystals were annealed in a butane/air flame and cooled down, following the procedure described by Clavilier et $a l .{ }^{46}$ A platinized Pt wire was used as the counter electrode, while the reference electrode was a reversible hydrogen electrode (RHE) prepared in the same solution, to which all the electrode potentials were referenced. The experiments were performed at $\sim 25{ }^{\circ} \mathrm{C}$. The electrode potential was controlled using a waveform generator (EG\&G PARC 175) together with a potentiostat (Amel 551) and a digital recorder (eDAC ED 401).

All the electrolyte solutions were $0.1 \mathrm{M} \mathrm{HClO}_{4}$ (Merck Suprapur) prepared in ultrapure water (Milli-Q, 18.2 M $\Omega \mathrm{cm}$ ). Argon (Alpha Gaz ${ }^{\mathrm{TM}}$, N50) was used for degassing the electrolyte solution. In order to obtain a $\mathrm{CO}$ adlayer in the $\mathrm{CO}$ stripping experiments, with the electrode potential fixed at $0.100 \mathrm{~V}$, a flow of CO (Alpha Gaz ${ }^{\mathrm{TM}}$, N47) was directly injected into the electrochemical cell for $5 \mathrm{~min}$, and the solution was degassed for 18 min to eliminate non-adsorbed CO (15 min in the case of the spectroelectrochemical experiments). The electrodeposition of $\mathrm{Sn}$ or $\mathrm{Ru}$ at the steps of a stepped Pt crystal was performed using dilute solutions $\left(\sim 10^{-5} \mathrm{M}\right.$, providing a low mass transport rate) of $\mathrm{RuCl}_{3} \cdot x \mathrm{H}_{2} \mathrm{O}$ (Merck) or $\mathrm{SnSO}_{4}$ (Merck) prepared in $0.1 \mathrm{M} \mathrm{HClO}_{4}$, with cycling of the electrode potential from $0.060 \mathrm{~V}$ to $0.300 \mathrm{~V}$, at a rate of $0.05 \mathrm{~V} \mathrm{~s}^{-1}$. The experiments were stopped when the desired degree of $\mathrm{Sn}$ or $\mathrm{Ru}$ coverage was reached, ascertained from suppression of the peak for hydrogen adsorption/desorption at the (110) steps on the stepped Pt crystal. The CO stripping experiments were carried out in another electrochemical cell free from $\mathrm{Sn}$ or $\mathrm{Ru}$. The Sn or Ru coverage at (110) steps (denoted as $\left.\theta_{i}^{\text {Step }}\right)$ of $\operatorname{Pt}(h k l)$ stepped surfaces was evaluated according to:

$$
\theta_{i}^{\text {Step }} \simeq \frac{Q_{\mathrm{H}}^{\text {Step }, 0}-Q_{\mathrm{H}}^{\text {Step }, i}}{Q_{\mathrm{H}}^{\text {Step }, 0}}
$$

where $i$ denotes the $\mathrm{Sn}$ or Ru at steps, and $Q_{\mathrm{H}}^{\mathrm{Step}, 0}$ and $Q_{\mathrm{H}}^{\mathrm{Step}, i}$ refer to the charge density of hydrogen desorption from (110) step sites on the clean stepped Pt surface and on the 
surface after its modification by deposition of $\mathrm{Sn}$ or $\mathrm{Ru}$, respectively. This analysis of heteroatoms coverage did not consider the stoichiometry between heteroatoms attached on the surface and the Pt atoms at steps, i.e., the absolute coverage of heteroatoms. However, in the case of Sn at (111) Pt terraces, Tillmann et al. ${ }^{47}$ and Rizo et al. ${ }^{38}$ estimated that each Sn atom blocks three Pt atoms at (111) terraces of the Pt surface.

The removal of either $\mathrm{Sn}$ or Ru from the modified Pt surfaces involved wetting the surface in concentrated nitric acid followed by heating in a butane/air flame until the small drop of nitric acid on the surface exploded, repeating the procedure about ten times, taking care to avoid the electrode becoming a red color in the flame. In the next step, blank voltammograms were recorded and $\mathrm{CO}$ stripping was performed after removal of the heteroatoms from the Pt surface. The CO stripping was compared to that before the deposition of heteroatoms, and any additional catalytic activity on the stepped Pt crystal surface (after removal of the heteroatoms) was detected. Further experiments involving new coverage of $\mathrm{Sn}$ or Ru were only performed after completing this careful procedure.

In spectro-electrochemical experiments, FTIR spectra were recorded in situ using a Nicolet 8700 spectrometer equipped with an MCT detector cooled with liquid $\mathrm{N}_{2}$. A thin layer configuration was achieved by pressing the face of the Pt crystal against a prismatic $\mathrm{CaF}_{2}\left(60^{\circ}\right)$ optical window in a spectro-electrochemical cell. ${ }^{48}$ Spectra were recorded from 0.060 to $0.800 \mathrm{~V}$ (at intervals of $50 \mathrm{mV}$ ), with each spectrum being the result of averaging $200 \mathrm{scans}$ at a resolution of $8 \mathrm{~cm}^{-1}$ (requiring $\sim 90 \mathrm{~s}$ for the acquisition of each spectrum). The spectra were presented in absorbance units:

$$
A=-\log \left[\left(R_{0}-R_{i}\right) / R_{0}\right] \text { versus } \mathrm{v} / \mathrm{cm}^{-1}
$$

where $R_{0}$ is the reference single-beam reflectance spectrum recorded at either $0.800 \mathrm{~V}$ or $0.010 \mathrm{~V}$, and $R_{i}$ is the single-beam reflectance spectrum recorded at the sample potential. Since it was desired to detect both adsorbed $\mathrm{CO}$ and dissolved $\mathrm{CO}_{2}$ in the thin layer, $p$ polarized radiation was employed, enabling the detection of IR-active species at both the electrode surface as well as in the thin layer, ${ }^{48}$ in accordance with the surface selection rule. $^{49,50}$

\section{Results}

\subsection{Electrochemical Characterization of the Electrodes}

Figure 2 shows a series of cyclic voltammograms corresponding to the $\operatorname{Pt}(554)$ and $\mathrm{Pt}(332)$ surfaces in $0.1 \mathrm{M} \mathrm{HClO}_{4}$ electrolyte solution, before and after deposition of $\mathrm{Sn}$ 
or Ru at their (110) steps. The upper potential limit for the cyclic voltammetry was set at $0.80 \mathrm{~V}$ in order to avoid dissolution of the foreign adatom from the electrode surfaces in the case of Sn and Ru deposited surfaces. The voltammetric profiles of the unmodified $\operatorname{Pt}(554)$ and $\operatorname{Pt}(332)$ indicated that the orientation of the crystal surfaces was of high quality and that stability was maintained over several voltammetric cycles.

As already shown, ${ }^{51}$ in Figure 2 , the sharp reversible peaks at $\sim 0.128 \mathrm{~V}$ were related to hydrogen desorption/adsorption (hydrogen underpotential deposition, $\mathrm{H}_{\text {upd }}$ ) at Pt steps with (110) orientation. The broad current feature below it corresponded to the $\mathrm{H}_{\text {upd }}$ at (111) Pt terrace sites. Further details of surface site assignment during the voltammetry can be found in the earlier work by Climent et al. ${ }^{51}$ When the stepped Pt surfaces were modified with Sn (Figures $2 \mathrm{~B}$ and $2 \mathrm{E}$ ) or Ru (Figures $2 \mathrm{C}$ and $2 \mathrm{~F}$ ), the evolution of the feature at $\sim 0.128 \mathrm{~V}$ reflected occupation of the step sites by $\mathrm{Sn}$ or $\mathrm{Ru}$, and it is remarkable that only the features corresponding to the $\mathrm{H}_{\text {upd }}$ at (110) step sites were affected. As reported previously, ${ }^{52,53}$ this indicates that $\mathrm{Sn}$ and $\mathrm{Ru}$ were preferentially adsorbed at steps of Pt, and that the sites ascribed as the (111) terraces only started to be occupied when the steps were fully occupied. Based on this information, the modified Pt stepped surfaces were denoted as $\mathrm{Sn}_{\text {steps }} / \mathrm{Pt}(h k l)$ and $\mathrm{Ru}_{\text {steps }} / \mathrm{Pt}(h k l)$ hetero-bimetallic surfaces, corresponding to the stepped Pt surfaces with steps occupied by $\mathrm{Sn}$ or $\mathrm{Ru}$, respectively. Using the equation 1 , different degrees of $\mathrm{Sn}$ or $\mathrm{Ru}$ coverage were determined for deposition on $\operatorname{Pt}(332)$ and $\operatorname{Pt}(554)$, as detailed below.

For the unmodified $\mathrm{Pt}(332)$ surface in Figure $2 \mathrm{~A}$ (or Figure $2 \mathrm{~B}$, black line), the charge density corresponding to the feature at $\sim 0.128 \mathrm{~V}$ was $\sim 27 \mu \mathrm{C} \mathrm{cm}^{-2}$, equivalent to $Q_{\mathrm{H}}^{\mathrm{Step}, 0}$. After blockage of (110) step sites by $\mathrm{Sn}$, the charge at this feature decreased to $\sim 22 \mu \mathrm{C} \mathrm{cm}^{-2}\left(Q_{\mathrm{H}}^{\mathrm{Step}, \mathrm{Sn}}\right)$, corresponding to $\theta_{\mathrm{Sn}}^{\text {Step }} \simeq 0.18$ (Figure $2 \mathrm{~B}$, red line). For another Sn deposition, the Sn coverage obtained was $\theta_{\mathrm{Sn}}^{\text {Step }} \simeq 0.48$ (blue line). Voltammetric profiles for the surfaces with greater Sn coverage are shown in Figure S1. It can be seen that the presence of a higher coverage of $\mathrm{Sn}$ started to disturb the profiles of the voltammograms in the double layer region, with an oxidation peak at $\sim 0.72 \mathrm{~V}$ and a reduction ranging from $\sim 0.71$ to $\sim 0.67 \mathrm{~V}$ appearing in the voltammograms. Rizo et al. ${ }^{38}$ reported that $\mathrm{Sn}$ at $\mathrm{Pt}$ presented an oxidation peak at potentials as low as $\sim 0.5 \mathrm{~V}_{\text {RHE. }}$ Considerations similar to those described above for the $\operatorname{Pt}(332)$ surface can be extended to the Sn-modified $\mathrm{Pt}(554)$ surface (Figure 2E). 
Figures $2 \mathrm{C}$ and $2 \mathrm{~F}$ show the voltammetric profiles for $\mathrm{Ru}$ electrodeposition at the (110) step sites of $\operatorname{Pt}(332)$ and $\operatorname{Pt}(554)$, respectively. Further data for Ru coverage at (110) steps are shown in Figure $\mathrm{S} 1$ for the $\operatorname{Pt}(332)$ and $\operatorname{Pt}(554)$ surfaces.

\subsection{Site-Specific Catalytic Activity by Cyclic Voltammetry}

The oxidative stripping of a CO adlayer on $\mathrm{Sn}_{\text {steps }} / \mathrm{Pt}(332)$ and $\mathrm{Ru}_{\text {steps }} / \mathrm{Pt}(332)$ is shown in Figure 3 for three coverages of $\mathrm{Sn}$ and $\mathrm{Ru}$, as well as for an unmodified $\mathrm{Pt}(332)$ surface. The $y$-axis was intentionally cut for better visualization of details in the currentpotential curve for voltammetric CO stripping on the modified stepped Pt surfaces. The CO stripping at a $\mathrm{Pt}(332)$ surface in acid solution occurred in a narrow potential window, with a single peak at $\sim 0.735 \mathrm{~V}$. In Figures $3 \mathrm{~A}$, it can be seen that the onset potential for $\mathrm{CO}$ stripping at $\mathrm{Sn}_{\text {steps }} / \mathrm{Pt}(332)$ was shifted to lower potentials, with the development of multiple oxidation peaks. At least three $\mathrm{CO}$ oxidation peaks could be identified, designated 1, 2, and 3, occurring at $\sim 0.424 \mathrm{~V}, \sim 0.60 \mathrm{~V}$, and $\sim 0.70 \mathrm{~V}$, respectively. Peak 3 for $\mathrm{Sn}_{\text {steps }} / \operatorname{Pt}\left(332\right.$ ) with $\theta_{\mathrm{Sn}}^{\text {Step }} \simeq 0.18$ (Figure $3 \mathrm{~A}$, blue line) involves at least two processes (designated 3 and 3'). As can be observed in Figure 3A, the onset potential of CO adlayer oxidation strongly depended on the coverage of $\mathrm{Sn}$ at the (110) steps of the $\operatorname{Pt}(332)$ surface. In this sense, for $\mathrm{Sn}_{\text {steps }} / \operatorname{Pt}(332)$ catalyst with $\theta_{\mathrm{Sn}}^{\text {Step }} \simeq 0.18$, the $\mathrm{CO}$ adlayer oxidation started at $\sim 0.38 \mathrm{~V}$ (Figure $3 \mathrm{~A}$, blue line), while for $\mathrm{Sn}_{\text {steps }} / \mathrm{Pt}(332)$ with $\theta_{\mathrm{Sn}}^{\mathrm{Step}} \simeq 1.0$, the onset potential of CO oxidation decreased to $\sim 0.27 \mathrm{~V}$ (Figure 3A, olive line). For both Sn-modified and unmodified $\mathrm{Pt}(332)$ surfaces, the CO oxidation ended only at $\sim 0.77 \mathrm{~V}$. This means that in the case of $\mathrm{Sn}_{\text {steps }} / \mathrm{Pt}(332)$ with $\theta_{\mathrm{Sn}}^{\text {Step }} \simeq 1.0$ (Figure $3 \mathrm{~A}$, olive line), for which the onset potential of $\mathrm{CO}$ oxidation was $\sim 0.27 \mathrm{~V}$, there was a very wide potential window $(\Delta E)$ of about $500 \mathrm{mV}$ within which the $\mathrm{Sn}_{\text {steps }} / \operatorname{Pt}(332)$ catalyst was active toward the $\mathrm{CO}$ oxidation. In the case of the unmodified $\operatorname{Pt}(332), \Delta E$ was only about $60 \mathrm{mV}$. It can be seen from Figure 3 that when $\theta_{\mathrm{Sn}}^{\text {Step }}$ was increased, the process responsible for the peaks marked as 3 (and 3') and 2 diminished, while that for the peak marked as 1 increased. The same trend in onset potential for the $\mathrm{CO}$ oxidation with Sn coverage was also observed by Rizo et al. ${ }^{38}$ for Pt(111) modified with Sn. Further data for the $\mathrm{CO}$ oxidation on $\mathrm{Sn}_{\text {steps }} / \mathrm{Pt}(332)$ at various $\theta_{\mathrm{Sn}}^{\text {Step }}$ values are provided in Figure S2. 
When $\mathrm{Pt}(332)$ was modified with $\mathrm{Ru}$ (Figures 3B), the $\mathrm{CO}$ oxidation started at a potential of $\sim 0.50 \mathrm{~V}$ for all the $\theta_{\mathrm{Ru}}^{\text {Step }}$. Even in the case of $\mathrm{Ru}_{\text {steps }} / \operatorname{Pt}(332)$ with $\theta_{\mathrm{Ru}}^{\text {Step }} \simeq$ 0.04 , where only about $4 \%$ of the (110) steps of the $\operatorname{Pt}(332)$ surface were modified with $\mathrm{Ru}$, the $\mathrm{CO}$ oxidation started at $\sim 0.50 \mathrm{~V}$. However, the feature at around $\sim 0.5 \mathrm{~V}$ in the voltammogram only appeared as a pre-wave of $\mathrm{CO}$ electro-oxidation, and a significant reaction started at potentials above $\sim 0.65 \mathrm{~V}$. The increase in $\theta_{\mathrm{Ru}}^{\mathrm{Step}}$ was accompanied by an abrupt increase in maximum current density at $\sim 0.51 \mathrm{~V}$. In general, the data shown in Figure $3 \mathrm{~B}$ revealed that the presence of $\mathrm{Ru}$ at the steps of a $\operatorname{Pt}(332)$ surface induced a downshift in the onset potential for $\mathrm{CO}$ oxidation, with multiple peaks appearing in the voltammetric profile (peaks 1, 2, and 3 in Figure $3 \mathrm{~B}$ ). The increase in $\theta_{\mathrm{Ru}}^{\text {Step }}$ caused a magnification of the process at $\sim 0.51 \mathrm{~V}$ designated as 1 , at the expense of the processes at $\sim 0.6$ and $0.7 \mathrm{~V}$, designated as 2 and 3, respectively. Moreover, after the modification of $\operatorname{Pt}(332)$ with $\mathrm{Ru}$, the potential window within which the $\mathrm{Ru}_{\text {steps }} / \operatorname{Pt}(332)$ surfaces presented catalytic activity was extended to $\Delta E \simeq 270 \mathrm{mV}$, with the $\mathrm{CO}$ oxidation starting at $\sim 0.50 \mathrm{~V}$ and ending at $\sim 0.77 \mathrm{~V}$. It is noteworthy that when $\theta_{\mathrm{Ru}}^{\mathrm{Step}} \simeq 1.0$, the $\mathrm{CO}$ oxidation process responsible for peak 3 disappeared completely, as found previously. However, in the case of $\theta_{\mathrm{Sn}}^{\text {Step }} \simeq 1.0$, the process responsible for peak 3 (and peak 3') still remained, indicating that oxidation at the potential of peak 3 persisted even when all the (110) Pt steps were fully covered with Sn (Figure 3A, olive line).

In the $\mathrm{CO}$ stripping experiments described above, the entire $\mathrm{CO}$ adlayer was stripped at once in a single potentiodynamic sweep and it was not possible to identify the types of sites that, when activated, were responsible for the features in the voltammogram. To overcome this, experiments were performed in which a $\mathrm{CO}$ adlayer was oxidized partially, with selection of an appropriate upper potential limit that only allowed a small part of the $\mathrm{CO}$ adlayer to be oxidized in each potential cycling. After removal of this small fraction of the CO adlayer, the next potentiodynamic sweep (P.S.) was used to record the hydrogen region, whose evolution over several partial potentiodynamic sweeps could provide useful information about surface site release after progressive oxidation of the CO layer. The results are displayed for $\mathrm{Sn}_{\text {steps }} / \mathrm{Pt}(332)$ with $\theta_{\mathrm{Sn}}^{\text {Step }} \simeq 0.48$ in Figure $4 \mathrm{~A}$ and for $\mathrm{Ru}_{\text {steps }} / \operatorname{Pt}(332)$ with $\theta_{\mathrm{Ru}}^{\text {Step }} \simeq 0.56$ in Figure 4B. As can be inferred from the second potentiodynamic sweep (blue line) in the hydrogen region, for the partial CO adlayer oxidation on each surface, in the first potentiodynamic sweep (red line), only those sites 
ascribed to the (111) terrace sites were released during $\mathrm{CO}$ adlayer oxidation. In the next potentiodynamic sweep, the (111) terrace sites continued to be released and the undercoordinated sites were only released when all the terrace sites had been freed. Since each potentiodynamic sweep corresponded to a value of $\mathrm{CO}$ coverage $\left(\theta_{\mathrm{CO}}\right)$, the onset potential for oxidation of the remaining $\mathrm{CO}$ adlayer progressively increased as the $\mathrm{CO}$ coverage decreased (Figure 4), until the final remaining CO layer was oxidized. It could be assumed that $\mathrm{CO}$ at the top of the (110) Pt steps was oxidized at the highest potentials, which were $\sim 0.727 \mathrm{~V}$ for the $\operatorname{Sn}_{\text {steps }} / \operatorname{Pt}(332)$ catalyst with $\theta_{\mathrm{Sn}}^{\mathrm{Step}} \simeq 0.48$ and $\sim 0.717 \mathrm{~V}$ in the case of $\mathrm{Ru}_{\text {steps }} / \operatorname{Pt}(332)$ with $\theta_{\mathrm{Ru}}^{\mathrm{Step}} \simeq 0.56$. The end of oxidation of the CO layer at $\sim 0.717-0.727$ $\mathrm{V}$ corresponded to the intrinsic catalytic activity at (110) Pt step sites of a stepped Pt surface with partial deposition of $\mathrm{Sn}$ or $\mathrm{Ru}$ on the steps. If the $\mathrm{CO}$ adlayer started to be oxidized at the most active sites, the progressive increase in the onset potential for oxidation of the remaining $\mathrm{CO}$ layer in each potentiodynamic sweep convincingly showed that these active sites were not occupied by $\mathrm{CO}_{\text {ads }}$ again after they had been released in the previous catalytic cycle. Indeed, if they had been occupied with $\mathrm{CO}_{\mathrm{ads}}$ from the remaining $\mathrm{CO}$ layer, this would be a direct consequence of the diffusion of $\mathrm{CO}_{\mathrm{ads}}$ during its oxidation, which would imply that all the onset potentials for oxidation of such a remaining $\mathrm{CO}$ layer should be at least similar. Actually, the pattern of the onset potential for $\mathrm{CO}$ oxidation (Figure 4) suggested that the $\mathrm{CO}$ molecules in the remaining $\mathrm{CO}$ layer behaved as immobile species.

The potential for CO oxidation at the top of the (110) Pt steps of a similar surface in a similar electrolyte (at a potential scan rate of $50 \mathrm{mV} \mathrm{s}^{-1}$ ) was found to be $\sim 0.72 \mathrm{~V} .^{54}$ Figures 5A and 5B show the potential peaks for $\mathrm{CO}$ oxidation at (110) steps of unmodified and modified $\operatorname{Pt}(332)$ with different $\theta_{\mathrm{Sn}}^{\text {Step }}$ and $\theta_{\mathrm{Ru}}^{\text {Step }}$, respectively, when CO was only adsorbed at (110) step sites (decorated CO steps experiments). The decorated CO steps decorated were obtained by selective oxidative removal of a $\mathrm{CO}_{\text {ads }}$ adlayer from the (111) terrace sites, as described previously for the Figure 4 experiments. The potential peak for $\mathrm{CO}$ oxidation was slightly shifted towards positive values after modification of the $\mathrm{Pt}(332)$ with Sn, with this shift being greater for higher coverage of Sn at the steps. This evidences that Sn slightly inhibits the catalytic activity at Pt under-coordinated sites with (110) orientation. In the case of Ru-modified $\mathrm{Pt}(332)$ surfaces, the catalytic activity at the (110) steps did not seem to be affected (Figures 5B). 
Following description of the data shown in Figure 4, a better interpretation can be provided of the data illustrated in Figure 3. Hence, in terms of surface site assignation, the $\mathrm{CO}$ oxidation peaks designated as 1 and 2 in Figures $3 \mathrm{~A}$ for the $\mathrm{Sn}_{\text {steps }} / \mathrm{Pt}(332)$ catalysts could be solely attributed to the oxidation of CO involving the (111) Pt terrace sites. In the potential range at which peak 3 appeared, the process included a combination of oxidation of $\mathrm{CO}$ at the (110) steps and the (111) terraces. The partial stripping procedure employed for the acquisition of the data shown in Figure 4 enabled interpretation of the features in the voltammogram resulting from the contributions of different active sites, in terms of surface atoms orientation (such as (111) terrace and (110) step sites). A similar interpretation could be made for $\mathrm{CO}$ oxidation using the $\mathrm{Ru}_{\text {steps }} / \mathrm{Pt}(332)$ catalyst (Figure 3B). In all cases in Figure 4, when the $\mathrm{CO}$ adlayer was partially oxidized, there was preferential CO oxidation at those sites ascribed to the (111) Pt terraces, with CO oxidation at the (110) Pt steps only occurring when all the CO attached at the (111) terraces had been oxidized.

A detailed examination of the voltammetric profiles for $\mathrm{CO}$ oxidation on the $\mathrm{Sn}_{\text {steps }} / \mathrm{Pt}(h k l)$ and $\mathrm{Ru}_{\text {steps }} / \mathrm{Pt}(h k l)$ surfaces was performed by extracting the results from Figure 3 for very similar $\mathrm{Sn}$ and $\mathrm{Ru}$ coverage, considering $\theta_{\mathrm{Sn}}^{\text {Step }} \simeq 0.48$ and $\sim 1.0$, and $\theta_{\mathrm{Ru}}^{\text {Step }} \simeq 0.56$ and $\sim 1.0$, as shown in Figure 6 . Direct comparison was made between the data shown in Figure 6A, and between the data in Figure 6B. The voltammetric profiles, in terms of catalytic activity, were dramatically different for the $\mathrm{Sn}_{\text {steps }} / \operatorname{Pt}(332)$ and $\mathrm{Ru}_{\text {steps }} / \mathrm{Pt}(332)$ surfaces with very similar $\theta_{i}^{\text {Step }}$, with the main difference being related to the different potential windows (from $\sim 0.24 \mathrm{~V}$ up to $0.77 \mathrm{~V}$ ) within which the catalysts presented the greatest and the least catalytic activity. The data illustrated in Figure 6A showed that Sn was more efficient in decreasing the onset potential of CO oxidation on $\mathrm{Sn}_{\text {steps }} / \mathrm{Pt}(332)$, compared to $\mathrm{Ru}$ on the $\mathrm{Ru}_{\text {steps }} / \mathrm{Pt}(332)$ catalyst. However, compared with the $\mathrm{Ru}_{\text {steps }} / \mathrm{Pt}$ (332) catalyst, the complete oxidation of a CO adlayer on the $\mathrm{Sn}_{\text {steps }} / \operatorname{Pt}(332)$ catalyst required a higher potential limit. A similar interpretation can be applied for the data shown in Figure 6B. For the CO oxidation on $\mathrm{Sn}_{\text {steps }} / \mathrm{Pt}(332)$, a small part of the process designated as peak 3 persisted within the potential zone for $\mathrm{CO}$ oxidation on $\operatorname{Pt}(332)$, even when $\theta_{\mathrm{Sn}}^{\text {Step }} \simeq 1.0$.

The results for evaluation of the catalytic activities of the $\mathrm{Sn}_{\text {steps }} / \mathrm{Pt}(554)$ and $\mathrm{Ru}_{\text {step }} / \operatorname{Pt}(554)$ catalysts are displayed in Figure 7. Selection was made of $\theta_{\mathrm{Sn}}^{\text {Step }} \simeq 1.0$ (black line) and $\theta_{\mathrm{Ru}}^{\mathrm{Step}} \simeq 1.0$ (red line). CO stripping at an adatom-free $\mathrm{Pt}(554)$ catalyst is 
also presented (blue line). The $\mathrm{Sn}_{\text {steps }} / \mathrm{Pt}(554)$ catalyst showed a lower onset potential for $\mathrm{CO}$ oxidation of $\sim 0.4 \mathrm{~V}$, but the reaction only significantly increased up to $\sim 0.63 \mathrm{~V}$ and ended at $\sim 0.77 \mathrm{~V}(\Delta E \simeq 370 \mathrm{mV})$. In the case of the $\mathrm{Ru}_{\text {steps }} / \mathrm{Pt}(554)$ catalyst, the $\mathrm{CO}$ oxidation only started at $\sim 0.56 \mathrm{~V}$, but the catalyst oxidized the entire CO layer in a very narrow potential window $(\Delta E \simeq 70 \mathrm{mV})$, compared to the $\mathrm{Sn}_{\text {steps }} / \operatorname{Pt}(554)$ catalyst. The data for $\mathrm{CO}$ oxidation at $\mathrm{Sn}_{\text {steps }} / \mathrm{Pt}(554)$ with different $\theta_{\mathrm{Sn}}^{\text {Step }}$ values are displayed in Figure S3.

\subsection{Spectro-Electrochemical Experiments}

Spectro-electrochemical experiments were performed in order to obtain further information concerning the catalytic activities of the modified stepped Pt surfaces. Firstly, the results obtained for the $\operatorname{Pt}(332)$ catalyst were compared with those for an unmodified $\operatorname{Pt}(332)$ surface, published previously by us. ${ }^{41}$ Figure 8 shows spectra corresponding to the oxidative stripping of a $\mathrm{CO}$ adlayer on the $\mathrm{Sn}_{\text {step }} / \mathrm{Pt}(332)$ catalyst with $\theta_{\mathrm{Sn}}^{\text {Step }} \simeq 0.65$. The spectra in Figure 8B were obtained employing a reference spectrum collected at 0.80 $\mathrm{V}$ (when the entire $\mathrm{CO}$ at the surface was oxidized), while for those in Figure 8A, a reference spectrum at $0.10 \mathrm{~V}$ was employed when $\mathrm{CO}_{2}$ was absent. In Figure 8B, two frequency bands could be attributed to the adsorbed CO. At $0.15 \mathrm{~V}$ (red line), a band centered at $\sim 2065 \mathrm{~cm}^{-1}$ was due to the combined vibrations of linearly bonded CO at (111) terraces of Pt, as well as CO at the (110) step sites free of Sn. Since $\sim 65 \%$ of the (110) steps was occupied by $\mathrm{Sn}$, it is reasonable to assume that the remainder of the (110) steps $(\sim 35 \%)$ were potentially available sites at which CO could attach. At $0.15 \mathrm{~V}$, for a $\mathrm{Pt}(332)$ surface, the $v_{\mathrm{CO}}{ }^{L}$ for a full CO coverage appeared centered at $\sim 2064 \mathrm{~cm}^{-1} .{ }^{41}$ Another band in this spectrum, centered at $\sim 1824 \mathrm{~cm}^{-1}$, could be attributed to the vibration of bridge bonded $\mathrm{CO}$ at (111) terrace sites. ${ }^{55,56}$ Bridge bonded $\mathrm{CO}$ was apparently not formed at the (110) steps of $\mathrm{Pt}^{57}$ The band due to linearly bonded $\mathrm{CO}\left(v_{\mathrm{CO}}{ }^{L}\right)$ showed a linear relationship with the electrode potential, with a Stark tuning effect of $\mathrm{d} v_{\mathrm{CO}} / \mathrm{d} E \simeq 28 \mathrm{~cm}^{-}$ ${ }^{1} \mathrm{~V}^{-1}$ from $0.1 \mathrm{~V}$ up to $\sim 0.3 \mathrm{~V}$, while $\mathrm{d} v \mathrm{CO}^{B} / \mathrm{d} E \simeq 46 \mathrm{~cm}^{-1} \mathrm{~V}^{-1}$ was obtained for the bridge bonded CO. In Figure 8A, the band centered at $\sim 2343 \mathrm{~cm}^{-1}$ was due to the stretching frequencies of $\mathrm{CO}_{2}$ dissolved in the thin layer, which appeared at $\sim 0.30 \mathrm{~V}$, the onset potential for $\mathrm{CO}$ oxidation on the $\mathrm{Sn}_{\text {steps }} / \operatorname{Pt}(332)$ catalyst with $\theta_{\mathrm{Sn}}^{\text {Step }} \simeq 0.65$, while for the $\operatorname{Pt}(332)$ catalyst, the onset potential for $\mathrm{CO}$ oxidation was $\sim 0.5 \mathrm{~V}_{\mathrm{RHE}}{ }^{41}$ 
At $\sim 0.55 \mathrm{~V}$, the band frequencies of linearly bonded CO are shifted from 2065 to $\sim 2042 \mathrm{~cm}^{-1}$ (Figure 8B). The band frequencies at $\sim 0.50 \mathrm{~V}$ are characteristic of CO adsorbed at the top of the step sites in acidic solution. ${ }^{41}$ At a lower potential $(0.15 \mathrm{~V})$, the band frequencies of CO adsorbed at step sites should appear at $2020 \mathrm{~cm}^{-1}$ (with $\mathrm{d} v \mathrm{CO}$, step $/ \mathrm{d} E \simeq 48 \mathrm{~cm}^{-1} \mathrm{~V}^{-1}$ ). The $\mathrm{CO}$ adsorbed at terrace sites presents a higher singleton frequency, compared to that at step sites. In the case of co-adsorption of $\mathrm{CO}$ at steps and terraces, the band frequencies of $\mathrm{CO}$ at terraces predominate, due to a shift of intensity to higher frequencies, at the expense of that at lower frequencies (due to the dipole-dipole coupling effect). ${ }^{58}$ The data illustrated in Figure $8 \mathrm{~B}$ reveal that the oxidation of $\mathrm{CO}$ at the top of the (110) steps of a $\mathrm{Sn}_{\text {steps }} / \operatorname{Pt}(332)$ surface occurs at a higher potential (presumably, these were the last adsorbed molecules to be oxidized). This finding supports the results

shown in Figure 4 for partial stripping of $\mathrm{CO}$ on a $\mathrm{Sn}_{\text {steps }} / \operatorname{Pt}(332)$ catalyst with $\theta_{\mathrm{Sn}}^{\text {Step }} \simeq$ 0.48 , by using cyclic voltammetry.

When a $\mathrm{CO}$ adlayer was deposited and then oxidized on the $\mathrm{Ru}_{\text {steps }} / \mathrm{Pt}(332)$ catalyst with $\theta_{\mathrm{Ru}}^{\text {Step }} \simeq 0.69$, at $0.15 \mathrm{~V}$ (Figure 9B), the spectrum exhibited a pair of band frequencies centered at $\sim 2064 \mathrm{~cm}^{-1}$ and at $\sim 1836 \mathrm{~cm}^{-1}$ (poorly defined band intensity), related to the frequencies of linearly and bridge bonded $\mathrm{CO}$, respectively. The band frequencies of linearly bonded $\mathrm{CO}$ at $0.15 \mathrm{~V}$ were similar to those observed for $\mathrm{Pt}(332)$, described above. ${ }^{41}$ It should be noted that the spectra were obtained using a reference spectrum recorded at $0.80 \mathrm{~V}$, while those in Figure 9A were calculated employing a reference spectrum collected at $0.10 \mathrm{~V}$ (when $\mathrm{CO}_{2}$ was absent). The Stark tuning effect for linearly bonded $\mathrm{CO}$ (Figure 9B) was $\mathrm{d} v_{\mathrm{CO}} / \mathrm{d} E \simeq 29 \mathrm{~cm}^{-1} \mathrm{~V}^{-1}$ from $0.1 \mathrm{~V}$ up to $\sim 0.35$ $\mathrm{V}$, while for bridge bonded $\mathrm{CO}, \mathrm{d} v_{\mathrm{CO}}{ }^{B} / \mathrm{d} E$ was very imprecise, because the band intensity was poorly defined. At the end of the oxidation of the CO adlayer, $v{ }_{\mathrm{CO}}{ }^{L}$ shifted to $\sim 2041$ $\mathrm{cm}^{-1}$ at $0.55 \mathrm{~V}$, characteristic of $\mathrm{CO}$ adsorbed at the (110) steps. ${ }^{41}$ As mentioned above, $\mathrm{CO}$ adsorbed at the (110) step sites on a $\mathrm{Ru}_{\text {steps }} / \mathrm{Pt}(332)$ catalyst with $\theta_{\mathrm{Ru}}^{\text {Step }} \simeq 0.69$ is only oxidized at the highest potential, in agreement with the cyclic voltammetry data in Figure 4, with $\mathrm{CO}$ adsorbed on those sites ascribed as the (111) terraces presumably being oxidized first, followed by the CO population at the top of the (110) steps.

\section{Discussion}

The catalytic properties of site-specific $\mathrm{Pt}$ on $\mathrm{Sn}_{\text {steps }} / \mathrm{Pt}(h k l)$ and $\mathrm{Ru}_{\text {steps }} / \mathrm{Pt}(h k l)$ hetero-bimetallic surfaces could be successfully studied by employing the oxidative 
stripping of the $\mathrm{CO}$ adlayer as a surface probe reaction. Depending on parameters such as the crystallographic orientation of the Pt sites, the width of the (111) terraces of the stepped Pt surface, and coverage of modifying atoms ( $\mathrm{Sn}$ and $\mathrm{Ru}$ ), different catalytic properties of Pt sites were found on the hetero-bimetallic surfaces, with similarities and dissimilarities, as detailed below.

\subsection{Site Selective Electro-deposition of Sn and Ru at Stepped Pt Surfaces}

The voltammetric profiles obtained for the stepped Pt surfaces modified with either $\mathrm{Sn}$ or $\mathrm{Ru}$ indicated that $\mathrm{Sn}$ and $\mathrm{Ru}$ preferentially deposited at low coordinated sites of $\mathrm{Pt}$, in agreement with previous findings. ${ }^{52,53}$ Carbonio et al. ${ }^{59}$ modified a $\mathrm{Pt}(332)$ surface by sputtering deposition of $\mathrm{Ru}$ and employed an ex situ scanning tunneling microscopy technique under ultra-high vacuum to show that at low total coverage ( $\left.\theta_{\mathrm{Ru}} \simeq 0.34 \mathrm{ML}\right)$, $\mathrm{Ru}$ growth occurred on steps, forming 1D and 2D (one and two dimensional) structures. It was shown that in addition to these structures, there was coexistence of additional bilayers for $\theta_{\mathrm{Ru}} \simeq 0.94 \mathrm{ML} .{ }^{59}$ The Ru electrodeposition data shown in Figure 2 are consistent with the results of Carbonio et al. ${ }^{59}$ with the initial stage of Ru attachment at Pt stepped surfaces blocking the feature in the voltammogram related to the hydrogen adsorption/desorption at step sites. To our knowledge, there have been no similar studies involving the deposition of Sn at Pt stepped surfaces.

\subsection{Catalytic Activity at Different Pt Sites on $S n_{\text {steps }} / P t(h k l)$ and $R u_{\text {steps }} / P t(h k l)$ Bimetallic Surfaces}

For both types of $\mathrm{Sn}_{\text {steps }} / \mathrm{Pt}(h k l)$ and $\mathrm{Ru}_{\text {steps }} / \mathrm{Pt}(h k l)$ hetero-bimetallic surfaces, the catalytic activities at sites on the (111) Pt terraces were improved by the presence of Sn or $\mathrm{Ru}$ at the Pt steps, as evidenced from the data shown in Figures 4, 8, and 9. In experiments with surfaces modified using $\mathrm{Sn}$ or $\mathrm{Ru}$ at $\theta_{i}^{\text {Step }}<1$, where step sites without deposited $\mathrm{Sn}$ or $\mathrm{Ru}$ were presumably available for the adsorption of $\mathrm{CO}$, the results (Figure 5B) indicated that Ru did not affect the catalytic activity at the (110) step sites. We previously found that this was true for different coverage of $\mathrm{Ru}$ at steps $\left(\theta_{\mathrm{Ru}}^{\mathrm{Step}}\right)$ of a $\operatorname{Pt}(554)$ surface. ${ }^{41}$ However, in the case of the $\operatorname{Sn}_{\text {steps }} / \operatorname{Pt}(h k l)$ surface with $\theta_{i}^{\text {Step }}<1$, the results (Figure 5A) showed that the catalytic activity of the (110) steps of $\operatorname{Pt}(332)$ that were free of Sn was slightly inhibited after the deposition of Sn. Comparison of the potential peaks for CO oxidation at (110) steps before and after modification with Sn 
revealed a slight shift of $\sim 15 \mathrm{mV}$ towards higher values (see inset in Figure 5A). The trend for this potential shift suggested slight contrasting effects on the catalytic activity at (111) terraces and (110) steps of a $\mathrm{Sn}_{\text {steps }} / \mathrm{Pt}(h k l)$ surface. Therefore, the slight inhibitory effect on catalytic activity at the (110) Pt steps was different to the effect observed previously for $\mathrm{CO}$ oxidation on $\mathrm{Ru}_{\text {steps }} / \mathrm{Pt}(h k l)$, showing that $\mathrm{Sn}$ and $\mathrm{Ru}$ tailored the catalytic activity differently in low-coordinated sites, such as the (110) step orientation. It is clear that the catalytic activity of the host $\mathrm{Pt}$ in $\mathrm{Sn}_{\text {steps }} / \mathrm{Pt}(h k l)$ and $\mathrm{Ru}_{\text {steps }} / \mathrm{Pt}(h k l)$ was significantly promoted only at the (111) terrace sites, with the catalytic activity being delicately balanced at the Pt step sites. In a general way, all these results evidence that the presence of either $\mathrm{Sn}$ or $\mathrm{Ru}$ leads to a non-uniform synergistic effect on the catalytic activity of different active $\mathrm{Pt}$ sites, in this case depending on the crystallographic orientation of the Pt sites in question (terrace or step/defect sites). Recently, a nonuniform alteration in the catalytic activity of a stepped Pt surface was reported when the chemical environments of Pt active sites at surfaces were extrinsically changed by altering the solution $\mathrm{pH} .{ }^{60}$ In the present case, non-uniform alterations in the catalytic activities of different Pt sites were obtained when the chemical environments of active Pt surface sites were intrinsically changed by deposition of foreign atoms at certain $\mathrm{Pt}$ atoms at the surface. However, although both $\mathrm{Sn}$ and $\mathrm{Ru}$ greatly improved the rate of $\mathrm{CO}$ electrooxidation at the (111) terraces of Pt, the underlying mechanisms of the catalytic effects of $\mathrm{Sn}$ and Ru were different, as presented below.

\subsection{Abilities of Sn and Ru in Site-Specific Tailoring of Catalytic Activity in the Host Pt}

Firstly, it is important to highlight that at the macroscopic scale, Sn seems to be completely inert towards CO adsorption, ${ }^{37,40,47}$ while CO adsorbs strongly on bulk Ru. ${ }^{9}$ $\mathrm{Sn}$ and $\mathrm{Ru}$ both present high affinity for the binding and dissociation of water. Therefore, the rate of nucleation of oxygen-containing species would be expected to be higher at $\mathrm{Sn}$ sites or at the interfaces of the Pt-Sn surface, than at the Pt-Ru interfaces, because at the interfaces of the Pt-Ru catalyst, $\mathrm{CO}_{\text {ads }}$ and $\mathrm{H}_{2} \mathrm{O}_{\text {activated }}$ species would compete for adsorption at similar sites of the Ru domains, while sites at Sn would only be available for the nucleation of oxygen-containing species. At first glance, this could help to explain the catalytic promotion effects of $\mathrm{Sn}$ and $\mathrm{Ru}$ on the activities of the Pt-Sn and Pt-Ru catalysts towards the $\mathrm{CO}$ electro-oxidation, in agreement with the classical bifunctional mechanism. However, in addition to this important difference related to the affinity for adsorption of $\mathrm{CO}$, there are other underlying properties that have not been considered in 
the mechanisms of enhancement of catalytic performance due to the presence of Sn and $\mathrm{Ru}$ in the Pt-Sn and Pt-Ru catalysts.

In addition to the slight effects of $\mathrm{Sn}$ and $\mathrm{Ru}$ on the catalytic activity of the (110) steps, described above, another important difference in the mechanisms of catalytic promotion in the Pt-Sn and Pt-Ru catalysts concerns the different abilities of the metals ( $\mathrm{Sn}$ and $\mathrm{Ru}$ ) in terms of influencing the activity along the (111) terraces of stepped $\mathrm{Pt}$ surfaces. This can be evaluated using stepped Pt surfaces with different width (111) terraces, and the $\operatorname{Pt}(554)$ and $\operatorname{Pt}(332)$ surfaces were used in the present work for this purpose. Figure 7 shows the results for oxidation of $\mathrm{CO}$ adlayers on $\operatorname{Pt}(554)$ surfaces modified with $\mathrm{Sn}$ and $\mathrm{Ru}$, where the surfaces of the (111) terraces were 9 atoms wide. For the $\mathrm{Sn}_{\text {steps }} / \operatorname{Pt}(554)$ surface with $\theta_{\mathrm{Sn}}^{\mathrm{Step}} \simeq 1.0$, the fact that the CO electro-oxidation started at $\sim 0.4 \mathrm{~V}$ and ended at $\sim 0.76 \mathrm{~V}$ indicated that the catalyst presented a highly heterogeneous "distribution" of activity at sites along the (111) terraces. In other words, the sites were activated in a wide potential window of $\Delta E \simeq 360 \mathrm{mV}$ on a $\mathrm{Sn}_{\text {steps }} / \operatorname{Pt}(554)$ surface with $\theta_{\mathrm{Sn}}^{\text {Step }} \simeq 1$.0. Since $\theta_{\mathrm{Sn}}^{\text {Step }} \simeq 1.0$, there were no Pt (110) step sites free for the adsorption of CO, because all the step sites contained deposited Sn. Therefore, all the Pt sites available for the adsorption/oxidation of CO lay along the (111) terraces. Hence, the small $\mathrm{CO}$ oxidation peak that appeared at around $0.5 \mathrm{~V}$ (details in Figure 7A') was probably due to the oxidation of $\mathrm{CO}$ at the (111) terrace sites. The $\mathrm{Sn}$ present on the $\mathrm{Sn}_{\text {steps }} / \mathrm{Pt}(554)$ surface was able to lower the onset potential of $\mathrm{CO}$ oxidation, but had little ability to promote any catalytic activity along the (111) terraces, because the rate of CO oxidation at (111) terraces only increased significantly at potentials above $\sim 0.63 \mathrm{~V}$ (Figure 7 , black line), reaching a maximum at $\sim 0.72 \mathrm{~V}$. On the other hand, the presence of $\mathrm{Ru}$ on the $\mathrm{Ru}_{\text {steps }} / \mathrm{Pt}(554)$ surface with $\theta_{\mathrm{Ru}}^{\text {Step }} \simeq 1.0$ (Figure 7, red line) made all the sites along the (111) terraces highly catalytically active at a potential lower than $0.63 \mathrm{~V}$. Furthermore, for the $\mathrm{Ru}_{\text {steps }} / \mathrm{Pt}(554)$ bimetallic surface, all the $\mathrm{CO}$ molecules were oxidized within a narrow potential window $(\Delta E \simeq 70 \mathrm{mV})$, with a maximum at $\sim 0.59 \mathrm{~V}$. Therefore, there was a highly homogeneous "distribution" of catalytic activity at the (111) terraces of a $\mathrm{Ru}_{\text {steps }} / \operatorname{Pt}(554)$ hetero-bimetallic surface with $\theta_{\mathrm{Ru}}^{\text {Step }} \simeq 1.0$, in contrast to the behavior observed for $\mathrm{CO}$ oxidation on the $\mathrm{Sn}_{\text {steps }} / \operatorname{Pt}(554)$ surface with $\theta_{\mathrm{Sn}}^{\mathrm{Step}} \simeq 1.0$.

When a similar analysis was performed for the $\mathrm{Sn}_{\text {steps }} / \mathrm{Pt}(332)$ catalyst, it was clear that reduction of the width of the (111) terrace to 5 atoms resulted in a significantly higher reaction rate (current density) for $\mathrm{CO}$ electro-oxidation at around $0.4 \mathrm{~V}$ (peak 1 in Figure 
$6 \mathrm{~A}$ - black line). However, even for a $\mathrm{Sn}_{\text {steps }} / \mathrm{Pt}(332)$ surface with $\theta_{\mathrm{Sn}}^{\text {Step }} \simeq 1.0$ (when all the (110) Pt steps were covered with deposited Sn), an appreciable current feature due to the $\mathrm{CO}$ oxidation at around $0.72 \mathrm{~V}$ (peak 3 in Figure $6 \mathrm{~B}$ - black line) still persisted, even at this high electrode potential. The process of $\mathrm{CO}$ stripping at $\sim 0.72 \mathrm{~V}$ on the $\mathrm{Sn}_{\text {steps }} / \mathrm{Pt}(332)$ surface with $\theta_{\mathrm{Sn}}^{\mathrm{Step}} \simeq 1.0$ can be unequivocally attributed to CO oxidation on the (111) terrace sites, because under this condition of $\mathrm{Sn}$ coverage, only the (111) Pt terrace sites were available for $\mathrm{CO}$ adsorption at the Sn-modified surface. Even at the $\mathrm{Sn}_{\text {steps }} / \mathrm{Pt}(332)$ surface with $\theta_{\mathrm{Sn}}^{\text {Step }} \simeq 1.0$, there were (111) Pt terrace sites that were not activated at the threshold potential for $\mathrm{CO}$ oxidation (starting at around $\sim 0.27 \mathrm{~V}$ ), requiring an elevated overpotential to become active. Therefore, the existence of $\mathrm{CO}$ oxidation at $\sim 0.72 \mathrm{~V}$ at the (111) terraces of a $\mathrm{Sn}_{\text {steps }} / \operatorname{Pt}(332)$ surface with $\theta_{\mathrm{Sn}}^{\mathrm{Step}} \simeq 1.0$ indicated that there must have been a portion of the (111) terrace sites where the behavior was not affected by the presence of Sn at the step sites. This was despite the fact that a portion of the sites at (111) Pt terraces (probably at terraces atomic row adjacent to the steps) became catalytically active at an extremely low potential $(\sim 0.27 \mathrm{~V})$. In this regard, the presence of $\mathrm{Sn}$ in $\mathrm{Sn}_{\text {steps }} / \operatorname{Pt}(332)$ surface, for example with $\theta_{\mathrm{Sn}}^{\mathrm{Step}} \simeq 0.48$, resulted in a reduction to $\sim 0.30 \mathrm{~V}$ of the onset potential for $\mathrm{CO}$ oxidation at the first row of atoms at the (111) steps (Figure 3A), while the CO oxidation at (110) Pt steps of the same catalyst presented a maximum at $\sim 0.733 \mathrm{~V}$ (Figure $5 \mathrm{~A}$ ). This confirmed that the presence of $\mathrm{Sn}$ at the Pt surface led to a large difference (in terms of the difference in overpotential, $\Delta \eta$ $\simeq 500 \mathrm{mV}$ ) in the catalytic activity of the atoms at the bottom side of the steps, compared to the catalytic activity at the top side of the step sites at a same catalyst surface (see the illustration in the Graphical Abstract). This evidences that the catalytic activity at the bottom side of the steps was significantly improved, while the activity at the top side of the steps was slightly inhibited. Therefore, despite the strong contribution of Sn to enhancement of the catalytic activity along the (111) terraces, the promoting effect only seemed to reach the first rows of atoms at the (111) terraces, presumably only affecting those atoms at terraces close to the steps where Sn was deposited. This suggests that the catalytic promotion effect of $\mathrm{Sn}$ acted over a very short distance, compared to the effect of $\mathrm{Ru}$ along the (111) terraces of a Pt stepped surface. Hence, from comparison of the catalytic activities of the $\mathrm{Sn}_{\text {steps }} / \operatorname{Pt}(332)$ and $\mathrm{Ru}_{\text {steps }} / \operatorname{Pt}(332)$ catalysts at similar $\theta_{i}^{\text {Step }}$ (data in panels A and B of Figure 6), it is clear that the catalytic effect of Sn was stronger at low potentials, relative to the effect of $\mathrm{Ru}$. Therefore, both $\mathrm{Sn}$ and $\mathrm{Ru}$ strongly influenced 
the catalytic activity along the (111) terraces of a stepped Pt surface, but showed different underlying mechanisms in terms of balancing the activity at the Pt sites.

The difference in the ways that $\mathrm{Sn}$ and $\mathrm{Ru}$ acted in catalytic promotion along the (111) terraces of a stepped Pt surface was probably due to different electronic interactions of $\mathrm{Sn}$ and $\mathrm{Ru}$ at the Pt sites. However, no differences in the stretching frequencies of $\mathrm{CO}$ $\left(v_{\mathrm{CO}}{ }^{i}\right.$ ) were detected among $\mathrm{Sn}_{\text {steps }} / \operatorname{Pt}(332), \mathrm{Ru}_{\text {steps }} / \mathrm{Pt}(332)$, and $\operatorname{Pt}(332)$, suggesting that the effects of $\mathrm{Sn}$ and $\mathrm{Ru}$ might occur in a $\mathrm{CO}$ electro-oxidation reaction step involving water activation/dissociation that was not identified from the results of the voltammetric and FTIR analyses.

\subsection{Consideration on the Mechanism of Electro-Oxidation of a CO Adlayer}

As shown in Figure 4, oxidation of the partial $\mathrm{CO}$ adlayer occurred with a progressive increase in the onset potential for CO oxidation along the (111) Pt terraces, consistent with the hypothesis that after the most active sites were released, they did not become occupied by $\mathrm{CO}_{\text {ads }}$ from the remaining $\mathrm{CO}$ layer. The absence of reoccupation of these most active sites, even when they were probably available, suggested either that $\mathrm{CO}_{\mathrm{ads}}$ behaved as an immobile species during its oxidation, or that the surface mobility of $\mathrm{CO}_{\text {ads }}$ during its electro-oxidation was too slow, considering the time scale of these experiments. Consequently, as shown in Figure 4, there was a relationship between the progressive increase in onset potential for oxidation of the remaining $\mathrm{CO}$ adlayer and the decrease in the remaining $\mathrm{CO}$ adlayer coverage, indicating that the process was governed by site activation, with the existence of catalytically active sites being dependent on the electrode potential. Therefore, the electro-oxidation of the $\mathrm{CO}$ adlayer was likely to start at the sites along the first row of atoms at the (111) Pt terrace sites, continuing with the involvement of sites along the (111) Pt terraces, even away from the modifying atoms ( $\mathrm{Sn}$ and $\mathrm{Ru}$ ), and ending with those $\mathrm{CO}$ molecules attached at the top of the Pt steps. Supporting this, it has been found previously that under electrochemical conditions, adsorbed CO forms nano-islands at the (111) terraces of Pt single crystals, ${ }^{61,62}$ as well as at polycrystalline Pt surfaces, ${ }^{63}$ with the oxidation of adsorbed $\mathrm{CO}$ starting at the edges of these nano-islands. ${ }^{62}$

Considering further the apparent immobility of $\mathrm{CO}$ during its oxidation, it should be highlighted that $\mathrm{CO}$ binds more strongly at low coordination sites than at close-packed domains, ${ }^{64,65}$ and that the electro-oxidation of $\mathrm{CO}$, coincidently, starts at sites where CO is more weakly bonded, probably involving sites at (111) terraces of the atomic row 
adjacent to the steps. ${ }^{66}$ Additional evidence to rule out the hypothesis of movement of $\mathrm{CO}_{\text {ads }}$ from other Pt domains to sites at the first row of atoms on (111) terraces is that the stabilization of $\mathrm{CO}$ at these sites was favored when the electrode was more negatively charged. ${ }^{54}$ Hence, at potentials at which the oxidation of a full $\mathrm{CO}$ adlayer occurred (higher than $\sim 0.27 \mathrm{~V}$, as shown in Figures 3, 8, and 9), this last condition of electrode more negatively charged was not fulfilled, considering the low potential that is usually applied for growing a $\mathrm{CO}$ adlayer (typically 0.05-0.10 $\mathrm{V}_{\mathrm{RHE}}$ ). Additionally, lateral interaction obviously plays a role in $\mathrm{CO}_{\text {ads }}$ surface diffusion, ${ }^{67,68}$ although the above considerations (unfavorable $\mathrm{CO}_{\text {ads }}$ diffusion during its oxidation) are applicable here under conditions in which the $\mathrm{CO}_{\mathrm{ads}}$ coverage progressively decreased at the catalyst surface, when lateral interaction among the adsorbate was (in principle) minimized. Therefore, as the CO electro-oxidation takes place at (111) terraces of Pt sites away from the modifying atom ( $\mathrm{Sn}$ or $\mathrm{Ru}$ ), and $\mathrm{CO}_{\mathrm{ads}}$ is apparently immobile during its oxidation, it can be concluded that the bifunctional mechanism is not an appropriate model for interpretation of the high catalytic activity of $\mathrm{Sn}_{\text {steps }} / \mathrm{Pt}(h k l)$ or $\mathrm{Ru}_{\text {steps }} / \mathrm{Pt}(h k l)$ bimetallic surfaces in CO stripping experiments.

Evidently, this raises another important problem, which is the mechanism responsible for supplying oxygen-containing species close to the $\mathrm{CO}_{\text {ads }}$ during its oxidation. An interpretation was suggested by Lee et al., ${ }^{16}$ who studied oxidative CO stripping on $\mathrm{Pt}$ nanoparticles modified with $\mathrm{RuO}_{x} \mathrm{H}_{y}$. As previously suggested by Massong et al. ${ }^{37}$ and Bergelin et al. ${ }^{69}$, it was proposed that at high CO coverage, the oxidation of a compressed $\mathrm{CO}$ adlayer started at potentials around $0.5 \mathrm{~V}_{\mathrm{RHE}}$, following an Eley-Rideal mechanism (with $\mathrm{CO}_{a d s}$ as an adsorbed species and $\mathrm{H}_{2} \mathrm{O}_{\text {activated }}$ as a nonadsorbed species), with a Langmuir-Hinshelwood mechanism (involving $\mathrm{OH}_{\text {ads }}$ and $\mathrm{CO}_{\mathrm{ads}}$ ) only becoming predominant at higher potentials. ${ }^{16}$ In order to verify this hypothesis, $\mathrm{CO}$ stripping experiments were performed using a $\mathrm{Ru}_{\text {steps }} / \mathrm{Pt}(h k l)$ surface with $\theta_{\mathrm{Ru}}^{\mathrm{Step}} \simeq 0.56$ in solutions modified with addition of different amounts of sodium chloride (Figure S4). The potential for CO stripping as a whole (including electro-oxidation of CO at steps) shifted to positive values, suggesting that the supply of oxygen-containing species was affected by the presence of chloride in the solution. This indicated that the reaction proceeded according to a Langmuir-Hinshelwood mechanism, rather than an Eley-Rideal mechanism. In this process, water activated at $\mathrm{Sn}$ or $\mathrm{Ru}$ sites could reach $\mathrm{CO}_{\text {ads }}$ at $\mathrm{Pt}$ sites everywhere on surface, or water molecules could be activated at 
neighboring $\mathrm{CO}_{\mathrm{ads}}$ at $\mathrm{Pt}$ sites. The first hypothesis would imply the existence of a nonequilibrium state of adsorption/desorption paths involving oxygen-containing species (see p. 354 of ref. $^{70}$ ), which was considered unlikely (see p. 356 of ref. $^{70}$ ). Moreover, if the activation of water occurred on modifying sites ( $\mathrm{Sn}$ or $\mathrm{Ru}$ ), with diffusion to $\mathrm{CO}_{\mathrm{ads}}$ at Pt sites everywhere on the surface, the different roles played by $\mathrm{Sn}$ and $\mathrm{Ru}$ in the mechanisms of catalytic promotion at (111) Pt terraces would imply that the water structure could be different in each case, because $\mathrm{Sn}$ and $\mathrm{Ru}$ present different abilities to influence the catalytic activity at (111) Pt terrace sites. However, we acknowledge that the nature of the oxygen-containing species that combine with $\mathrm{CO}_{\text {ads }}$ to form $\mathrm{CO}_{2}$ remains an open question, as does the mechanism of transport of such species to $\mathrm{CO}_{\text {ads }}$ at specific sites on the catalyst surface.

\section{Conclusions}

This work provides unambiguous information necessary for the design of highly active sites on $\mathrm{Sn} / \mathrm{Pt}(h k l)$ and $\mathrm{Ru} / \mathrm{Pt}(h k l)$ bimetallic catalysts. In $\mathrm{Sn}_{\text {steps }} / \mathrm{Pt}(h k l)$ and $\mathrm{Ru}_{\text {steps }} / \mathrm{Pt}(h k l)$ catalysts, we found that $\mathrm{Sn}$ and $\mathrm{Ru}$ act to non-uniformly balance the catalytic activity of all the Pt sites, having the following specificity:

$i$. The synergistic effect of $\mathrm{Sn}$ or $\mathrm{Ru}$ at (110) steps only benefited catalytic activity at (111) Pt terraces sites, with Ru apparently not affecting the catalytic activity at the (110) Pt step sites. Sn, on the other hand, induced a slight inhibition of catalytic activity at the (110) Pt step sites. The non-uniform balancing of catalytic activity at Pt sites depended on the crystallographic orientation of the Pt sites in question, whether (111) terrace or low-coordinated sites (steps). Moreover, in the case of the Sn-modified stepped Pt surface, this foreign atom can interestingly act dually as a promoter (for the (111) Pt terraces) and as a weak inhibitor (for the (110) Pt steps).

ii. Despite the lower onset potential for CO electro-oxidation on the $\operatorname{Sn}_{\text {steps }} / \operatorname{Pt}(h k l)$ catalyst, compared to the $\mathrm{Ru}_{\text {steps }} / \mathrm{Pt}(h k l)$ catalyst, $\mathrm{Sn}$ only appeared to benefit catalytic activity at sites in the first rows of atoms at (111) Pt terraces close to the steps, while the enhancement due to Ru extended further along the (111) terrace sites. Therefore, $\mathrm{Sn}$ and $\mathrm{Ru}$ enhanced the catalytic activity according to different underlying mechanisms that were dependent on the proximity and orientation of the Pt sites.

iii. We propose that the initiation of oxidation of a CO adlayer on either $\mathrm{Sn}_{\text {steps }} / \mathrm{Pt}(h k l)$ or $\mathrm{Ru}_{\text {steps }} / \mathrm{Pt}(h k l)$ bimetallic surfaces involves $\mathrm{Pt}$ sites located at terrace atomic rows adjacent to the steps. The process continues along the (111) Pt terrace sites and ends 
with the involvement of sites at the (110) Pt steps. In this model, the entire process is controlled by the activation of the sites, rather than by the diffusion of $\mathrm{CO}_{\text {ads }}$ (during its oxidation) from other Pt sites towards the most active sites, which implies failure of the classical bifunctional mean-field mechanism as a model of catalytic promotion in oxidative CO stripping on these bimetallic catalysts. Therefore, the key step is the transport of oxygen-containing species to $\mathrm{CO}_{\mathrm{ads}}$, rather than diffusion of $\mathrm{CO}_{\text {ads }}$ to sites occupied by oxygen-containing species.

\section{Associated Content}

\section{Supporting Information}

Additional experimental results, including the cyclic voltammetry and in situ FTIR data, are provided in a PDF file.

Acknowledgements: M.J.S. Farias acknowledges financial support from PNPD/CAPES (Brazil). A.A. Tanaka acknowledges support from CAPES (PROCAD 2013) and CNPq (grant \#309066/2013-1). J.M. Feliu thanks MINECO (Project CTQ2016-76221-P) and GV (Project PROMETEOII/2014/013) for financial support. W. Cheuquepan is grateful for the award of a F.P.I. grant associated to project CTQ2009-13142. 


\section{References}

(1) Schlögl, R. Angew. Chem., Int. Ed. 2015, 54, 3465-3520.

(2) O’Neill, B. J.; Jackson, D. H. K.; Lee, J.; Canlas, C.; Stair, P. C.; Marshall, C. L.; Elam, J. W.; Kuech, T. F.; Dumesic, J. A.; Huber, G. W. ACS Catal. 2015, 5, 18041825.

(3) Mistry, H.; Varela, A. S.; Kühl, S.; Strasser, P.; Cuenya, B. R. Nat. Rev. Mater. 2016, 1, 16009.

(4) Singh, A. K.; Xu, Q. ChemCatChem 2013, 5, 652-676.

(5) P. Mercer, M.; E. Hoster, H. Nano Energy 2016, 29, 394-413.

(6) Ruth, K.; Vogt, M.; Zuber, R. In Handbook of Fuel Cells, 1st ed.; Wielstich, W., Gastieger, H. A., Eds.; John Wiley \& Sons, Ltd.: New York, 2009; Vol. 5, DOI: 10.1002/9780470974001.f303043.

(7) Garcia, A. C.; Paganin, V. A.; Ticianelli, E. A. Electrochim. Acta 2008, $53,4309-4315$.

(8) Buurmans, I. L. C.; Weckhuysen, B. M. Nat. Chem. 2012, 4, 873-886.

(9) Lin, W. F.; Zei, M. S.; Eiswirth, M.; Ertl, G.; Iwasita, T.; Vielstich, W. J. Phys. Chem. B 1999, 103, 6968-6977.

(10) Liu, P.; Logadottir, A.; Nørskov, J. K. Electrochim. Acta 2003, 48, 37313742.

(11) Takeguchi, T.; Kunifuji, A.; Narischat, N.; Ito, M.; Noguchi, H.; Uosaki, K.; Mukai, S. R. Catal. Sci. Technol. 2016, 6, 3214-3219.

(12) Pinheiro, A. L. N.; Zei, M. S.; Ertl, G. Phys. Chem. Chem. Phys. 2005, 7, 1300-1309.

(13) Watanabe, M.; Motoo, S. J. Electroanal. Chem. 1975, 60, 267-273.

(14) Motoo, S.; Watanabe, M. J. Electroanal. Chem. 1976, 69, 429-431.

(15) Wang, H.; Abruña, H. D. J. Phys. Chem. Lett. 2015, 6, 1899-1906.

(16) Lee, M. J.; Kang, J. S.; Kang, Y. S.; Chung, D. Y.; Shin, H.; Ahn, C. Y.; Park, S.; Kim, M. J.; Kim, S.; Lee, K. S.; Sung, Y. E. ACS Catal. 2016, 6, 2398-2407.

(17) Dimakis, N.; Iddir, H.; Díaz-Morales, R. R.; Lia, R.; Bunker, G.; Chung, E. H.; Smotkin, E. S. J. Phys. Chem. B 2005, 109, 1839-1848.

(18) Liu, P.; Nørskov, J. K. Fuel Cells 2001, 1, 192-201.

(19) Bandarenka, A. S.; Varela, A. S.; Karamad, M.; Calle-Vallejo, F.; Bech, L.; Perez-Alonso, F. J.; Rossmeisl, J.; Stephens, I. E. L.; Chorkendorff, I. Angew. Chem., Int. Ed. 2012, 51, 11845-11848.

(20) Kühl, S.; Strasser, P. Top. Catal. 2016, 1-10.

(21) Temmel, S. E.; Fabbri, E.; Pergolesi, D.; Lippert, T.; Schmidt, T. J. ACS Catal. 2016, 7566-7576.

(22) Kitchin, J. R.; Nørskov, J. K.; Barteau, M. A.; Chen, J. G. Phys. Rev. Lett. 2004, 93, 156801.

(23) Temmel, S. E.; Fabbri, E.; Pergolesi, D.; Lippert, T.; Schmidt, T. J. Adv. Mater. Interfaces 2016, 3, 1600222-n/a.

(24) Marković, N. M.; Ross Jr, P. N. Surf. Sci. Rep. 2002, 45, 117-229.

(25) Spendelow, J. S.; Wieckowski, A. Phys. Chem. Chem. Phys. 2004, 6, 5094-5118.

(26) Rau, M. S.; Gennero De Chialvo, M. R.; Chialvo, A. C. J. Power Sources 2012, 216, 464-470.

(27) Friedrich, K. A.; Geyzers, K. P.; Linke, U.; Stimming, U.; Stumper, J. J. Electroanal. Chem. 1996, 402, 123-128.

(28) Lu, G. Q.; Waszczuk, P.; Wieckowski, A. J. Electroanal. Chem. 2002, $532,49-55$. 
(29) Maillard, F.; Lu, G. Q.; Wieckowski, A.; Stimming, U. J. Phys. Chem. B 2005, 109, 16230-16243.

(30) Davies, J. C.; Hayden, B. E.; Pegg, D. J.; Rendall, M. E. Surf. Sci. 2002, 496, 110-120.

(31) Koper, M. T. M.; Lebedeva, N. P.; Hermse, C. G. M. Faraday Discuss. 2002, 121, 301-311.

(32) Katayama, Y.; Okanishi, T.; Muroyama, H.; Matsui, T.; Eguchi, K. ACS Catal. 2016, 6, 2026-2034.

(33) Mueller, J. E.; Krtil, P.; Kibler, L. A.; Jacob, T. Phys. Chem. Chem. Phys. 2014, 16, 15029-15042.

(34) Gasteiger, H. A.; Markovic, N.; Ross, P. N.; Cairns, E. J. J. Phys. Chem. 1994, 98, 617-625.

(35) Lin, W. F.; Iwasita, T.; Vielstich, W. J. Phys. Chem. B 1999, 103, 32503257.

(36) Hayden, B. E.; Rendall, M. E.; South, O. J. Am. Chem. Soc. 2003, 125, $7738-7742$.

(37) Massong, H.; Tillmann, S.; Langkau, T.; Abd El Meguid, E. A.; Baltruschat, H. Electrochim. Acta 1998, 44, 1379-1388.

(38) Rizo, R.; Pastor, E.; Koper, M. T. M.. J. Electroanal. Chem. 2016. DOI:10.1016/j.jelechem.2016.10.014

(39) Stamenković, V. R.; Arenz, M.; Lucas, C. A.; Gallagher, M. E.; Ross, P. N.; Marković, N. M. J. Am. Chem. Soc. 2003, 125, 2736-2745.

(40) Wang, K.; Gasteiger, H. A.; Markovic, N. M.; Ross Jr, P. N. Electrochim. Acta 1996, 41, 2587-2593.

(41) Farias, M. J. S.; Cheuquepan, W.; Camara, G. A.; Feliu, J. M. ACS Catal. 2016, 6, 2997-3007.

(42) Korzeniewski, C.; Climent, V.; Feliu, J. M. Electrochemistry at Platinum Single Crystal Electrodes. In Electroanalytical Chemistry. A Series of Advances, 24. A.J. Bard, C.G. Zoski (Eds.). CRC Press, 2012, pp. 75-170.

(43) Lang, B.; Joyner, R. W.; Somorjai, G. A. Surf. Sci. 1972, 30, 440-453.

(44) Clavilier, J.; El Achi, K.; Rodes, A. Chem. Phys. 1990, 141, 1-14.

(45) Rodes, A.; El Achi, K.; Zamakhchari, M. A.; Clavilier, J. J. Electroanal. Chem. 1990, 284, 245-253.

(46) Clavilier, J.; Faure, R.; Guinet, G.; Durand, R. J. Electroanal. Chem. 1980, 107, 205-209.

(47) Tillmann, S.; Samjeské, G.; Friedrich, K. A.; Baltruschat, H. Electrochim. Acta 2003, 49, 73-83.

(48) Iwasita, T.; Nart, F. C. Prog. Surf. Sci. 1997, 55, 271-340.

(49) Greenler, R. G. J. Chem. Phys. 1966, 44, 310-315.

(50) Hansen, W. N. J. Opt. Soc. Am. 1968, 58, 380-390.

(51) Climent, V.; García-Araez, N.; Herrero, E.; Feliu, J. Russ. J. Electrochem. 2006, 42, 1145-1160.

(52) Massong, H.; Wang, H.; Samjeské, G.; Baltruschat, H. Electrochim. Acta 2000, 46, 701-707.

(53) Samjeské, G.; Xiao, X. Y.; Baltruschat, H. Langmuir 2002, 18, 4659-4666.

(54) Farias, M. J. S.; Camara, G. A.; Feliu, J. M. J. Phys. Chem. C 2015, 119, 20272-20282.

(55) Villegas, I.; Weaver, M. J. J. Chem. Phys. 1994, 101, 1648-1660.

(56) Rodes, A.; Gómez, R.; Feliu, J. M.; Weaver, M. J. Langmuir 2000, 16, 811-816. 
(57) Chen, Q. S.; Berna, A.; Climent, V.; Sun, S. G.; Feliu, J. M. Phys. Chem. Chem. Phys. 2010, 12, 11407-11416.

(58) Persson, B. N. J.; Ryberg, R. Phys. Rev. B 1981, 24, 6954-6970.

(59) Carbonio, E. A.; Prieto, M. J.; De Siervo, A.; Landers, R. J. Phys. Chem. C 2014, 118, 28679-28688.

(60) Farias, M. J. S.; Mello, G. A. B.; Tanaka, A. A.; Feliu, J. M. J. Catal. 2017, 345, 216-227. 347-360.

(61) Furuya, N.; Motto, S.; Kunimatsu, K. J. Electroanal. Chem. 1988, 239,

(62) Chang, S. C.; Weaver, M. J. J. Chem. Phys. 1990, 92, 4582-4594.

(63) Chen, Y. X.; Heinen, M.; Jusys, Z.; Behm, R. J. J. Phys. Chem. C 2007, $111,435-438$.

(64) Tränkenschuh, B.; Fritsche, N.; Fuhrmann, T.; Papp, C.; Zhu, J. F.; Denecke, R.; Steinrück, H. P. J. Chem. Phys. 2006, 124.

(65) Vattuone, L.; Savio, L.; Rocca, M. Surf. Sci. Rep. 2008, 63, 101-168.

(66) Farias, M. J. S.; Herrero, E.; Feliu, J. M. J. Phys. Chem. C 2013, 117, $2903-$ 2913.

(67) Briner, B. G.; Doering, M.; Rust, H.-P.; Bradshaw, A. M. Science 1997, $278,257-260$.

(68) Gómez-Marín, A. M.; Hernández-Ortiz, J. P. J. Phys. Chem. C 2014, 118, $2475-2486$.

(69) Bergelin, M.; Herrero, E.; Feliu, J. M.; Wasberg, M. J. Electroanal. Chem. 1999, 467, 74-84.

(70) General Discussion. Faraday Discuss. 2002, 121, 331-364. DOI: 10.1039/B205675P. 


\section{Figures}

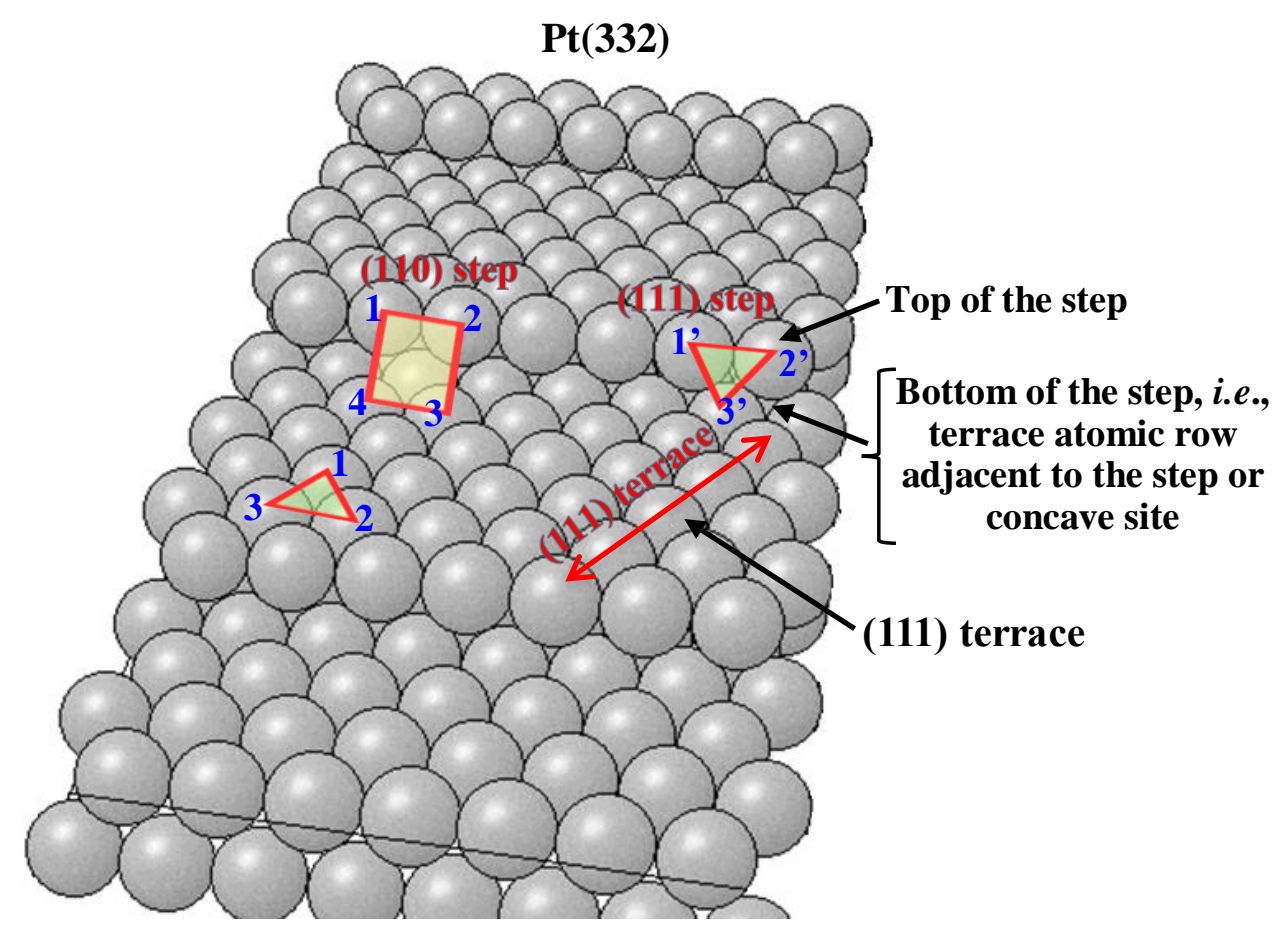

Figure 1. Hard sphere models corresponding to two Pt(111) vicinal stepped surfaces, having either (110) or (100) steps. Data drawn from: http://surfexp.fhi-berlin.mpg.de/ 

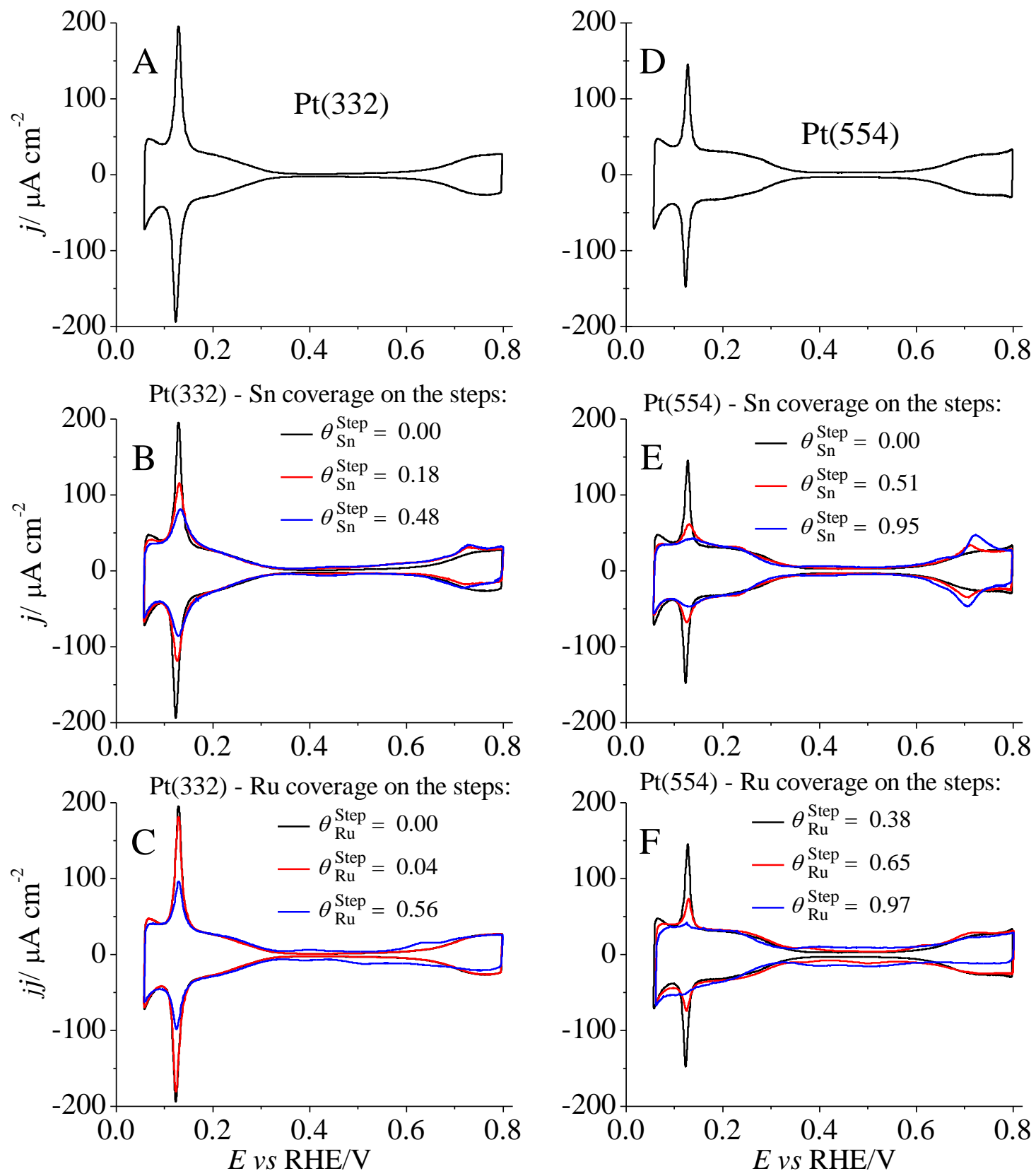

Figure 2. Cyclic voltammetry of two stepped Pt electrodes before (A and D) and after (B, C, E, and F) selective modifications of their steps by $\mathrm{Sn}(\mathrm{B}$ and $\mathrm{E})$ or $\mathrm{Ru}(\mathrm{C}$ and F). Data recorded at $0.05 \mathrm{~V} \mathrm{~s}^{-1}$ in $0.1 \mathrm{M} \mathrm{HClO}_{4}$. 

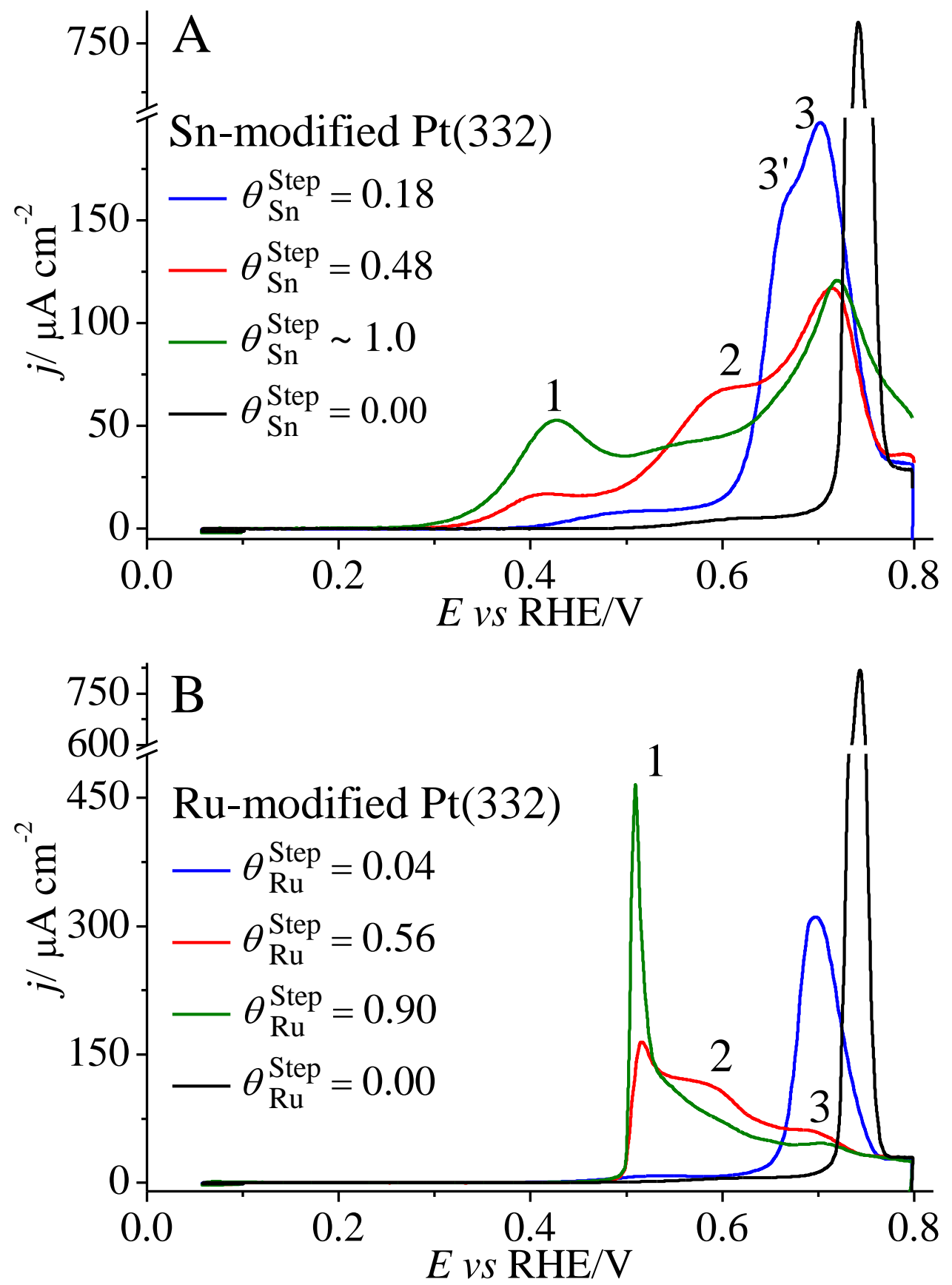

Figure 3. CO adlayer oxidation on $\mathrm{Pt}(332)$ and on stepped electrodes modified with $\mathrm{Sn}$ (A) and $\mathrm{Ru}(\mathrm{B})$. Data recorded at $0.05 \mathrm{~V} \mathrm{~s}^{-1}$ in $0.1 \mathrm{M} \mathrm{HClO}_{4}$. 

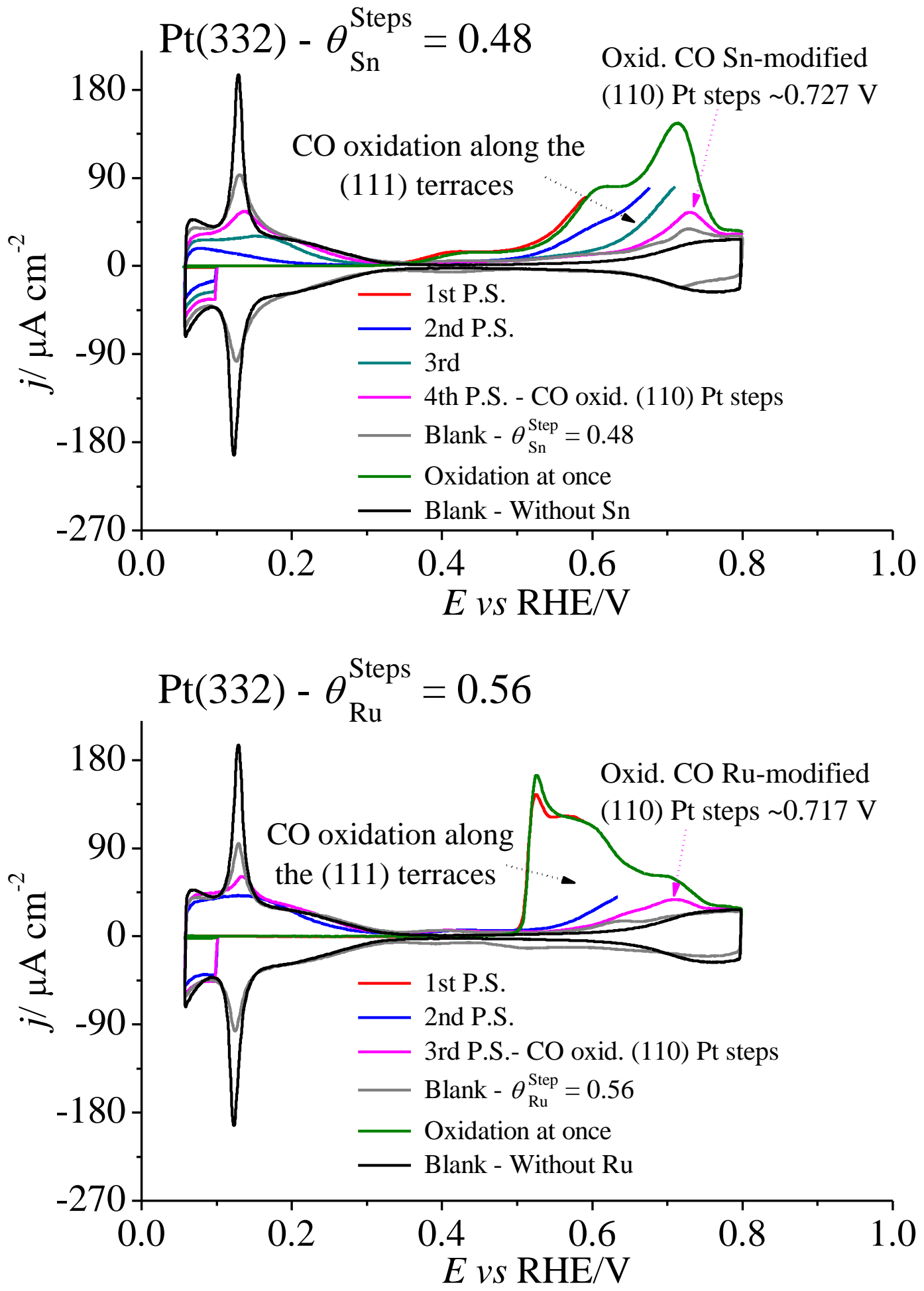

Figure 4. Successive voltammograms collected during the oxidation of $\mathrm{CO}$ adlayers on $\mathrm{Pt}(332)$ and with their steps modified by $\mathrm{Sn}$ or Ru (indicated). A blank voltammetric scan is shown for comparison. Data recorded at $0.05 \mathrm{~V} \mathrm{~s}^{-1}$ in $0.1 \mathrm{M} \mathrm{HClO}_{4}$. P.S. means potentiodynamic sweep. 

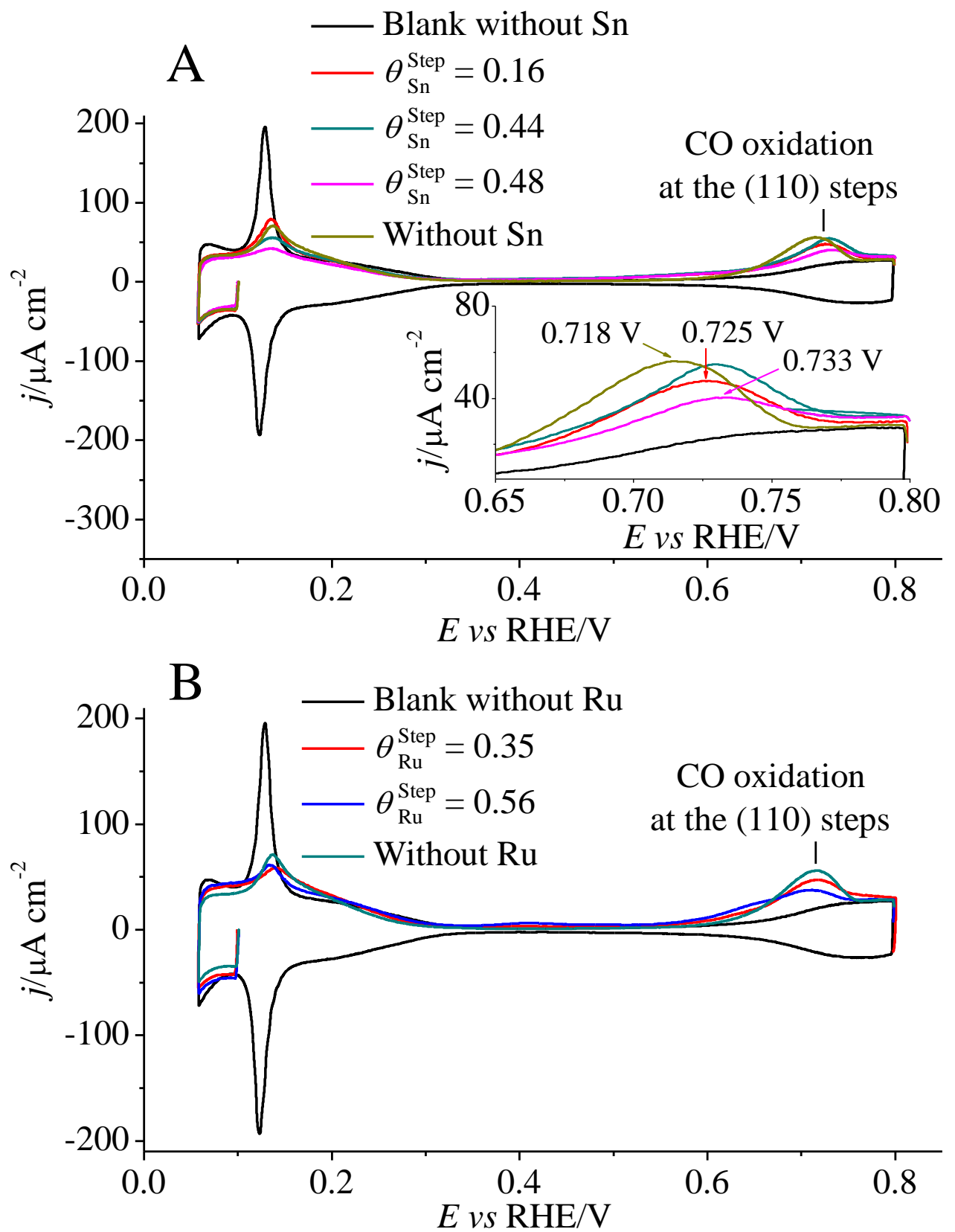

Figure 5. Adsorbed CO only on step sites. CO oxidation at the (110) steps of (A) Snmodified $\operatorname{Pt}(332)$ and (B) Ru-modified $\operatorname{Pt}(332)$ (coverages $\theta_{i}^{\text {Step }}$ as indicated) in $0.1 \mathrm{M}$ $\mathrm{HClO}_{4}$. Data recorded at $0.05 \mathrm{~V} \mathrm{~s}^{-1}$. 

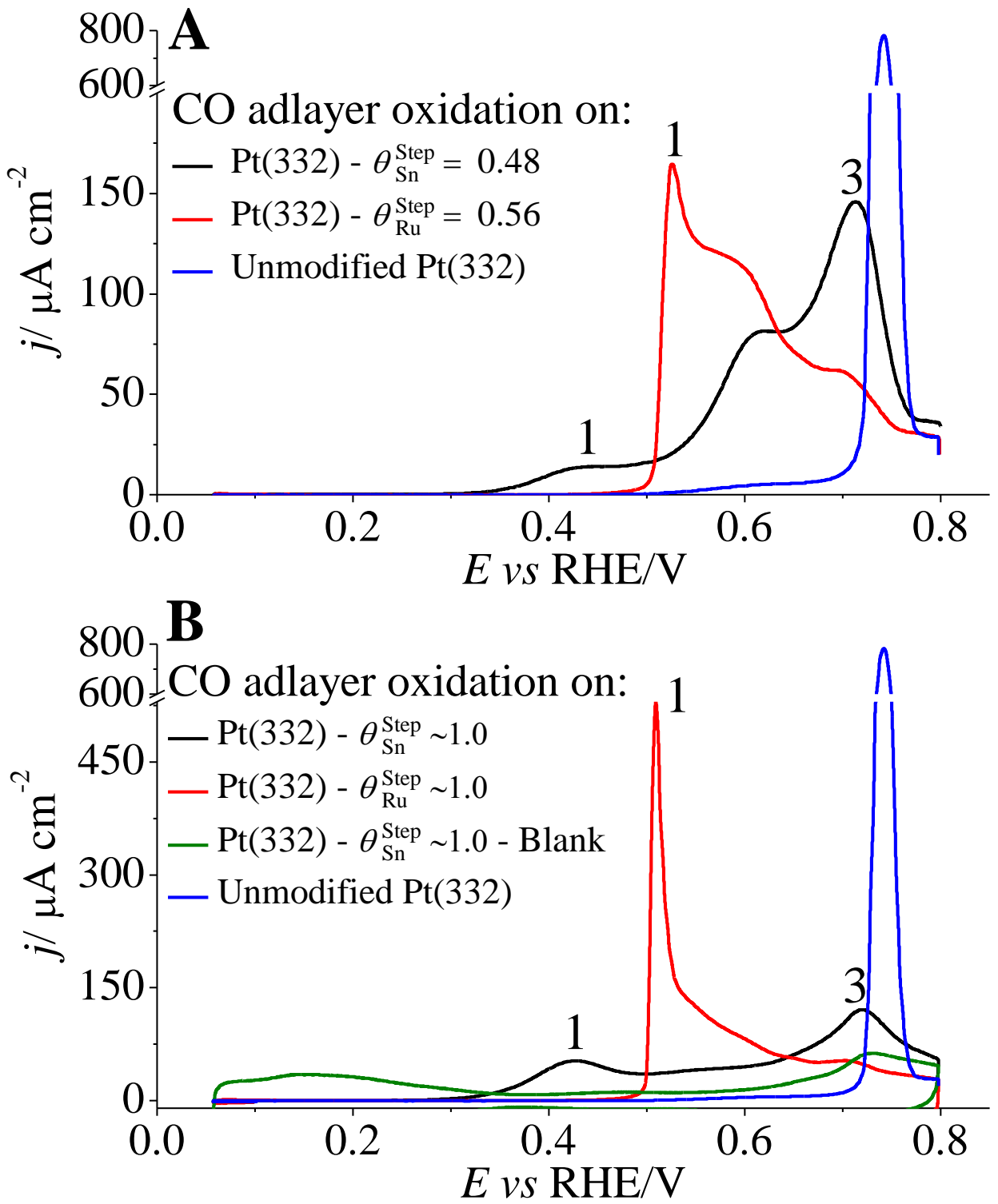

Figure 6. Comparison of catalytic activity for $\mathrm{CO}$ adlayer oxidation on: (A) $\mathrm{Sn}_{\text {steps }} / \mathrm{Pt}(332)$ and (B): $\mathrm{Ru}_{\text {steps }} / \mathrm{Pt}(332)$ surfaces. Also shown are blank voltammetric scans for the modified $\operatorname{Pt}(332)$ surfaces. 

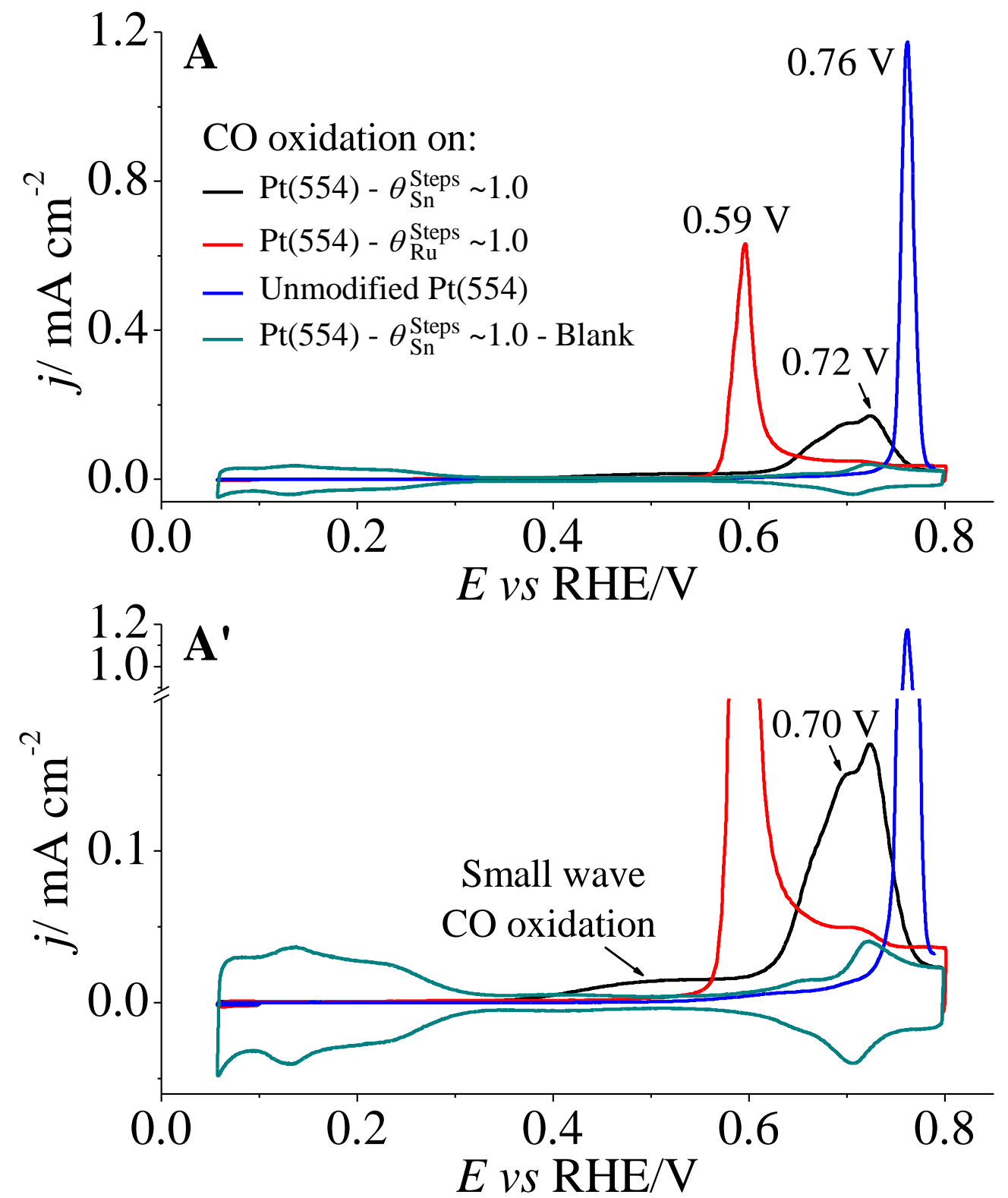

Figure 7. Oxidation of a full $\mathrm{CO}$ adlayer. (A) Comparison between $\mathrm{Sn}_{\text {steps }} / \mathrm{Pt}(554)$ with $\theta_{\mathrm{Sn}}^{\text {Step }} \simeq 1.0$ and $\mathrm{Ru}_{\text {steps }} / \operatorname{Pt}(554)$ with $\theta_{\mathrm{Ru}}^{\text {Step }} \simeq 1.0$. Also included is an oxidative $\mathrm{CO}$ stripping experiment using unmodified $\mathrm{Pt}(554)$. (A') Correspond to the A presented using an different scale. Data recorded in $0.1 \mathrm{M} \mathrm{HClO}_{4}$ at $0.05 \mathrm{~V} \mathrm{~s}^{-1}$. 


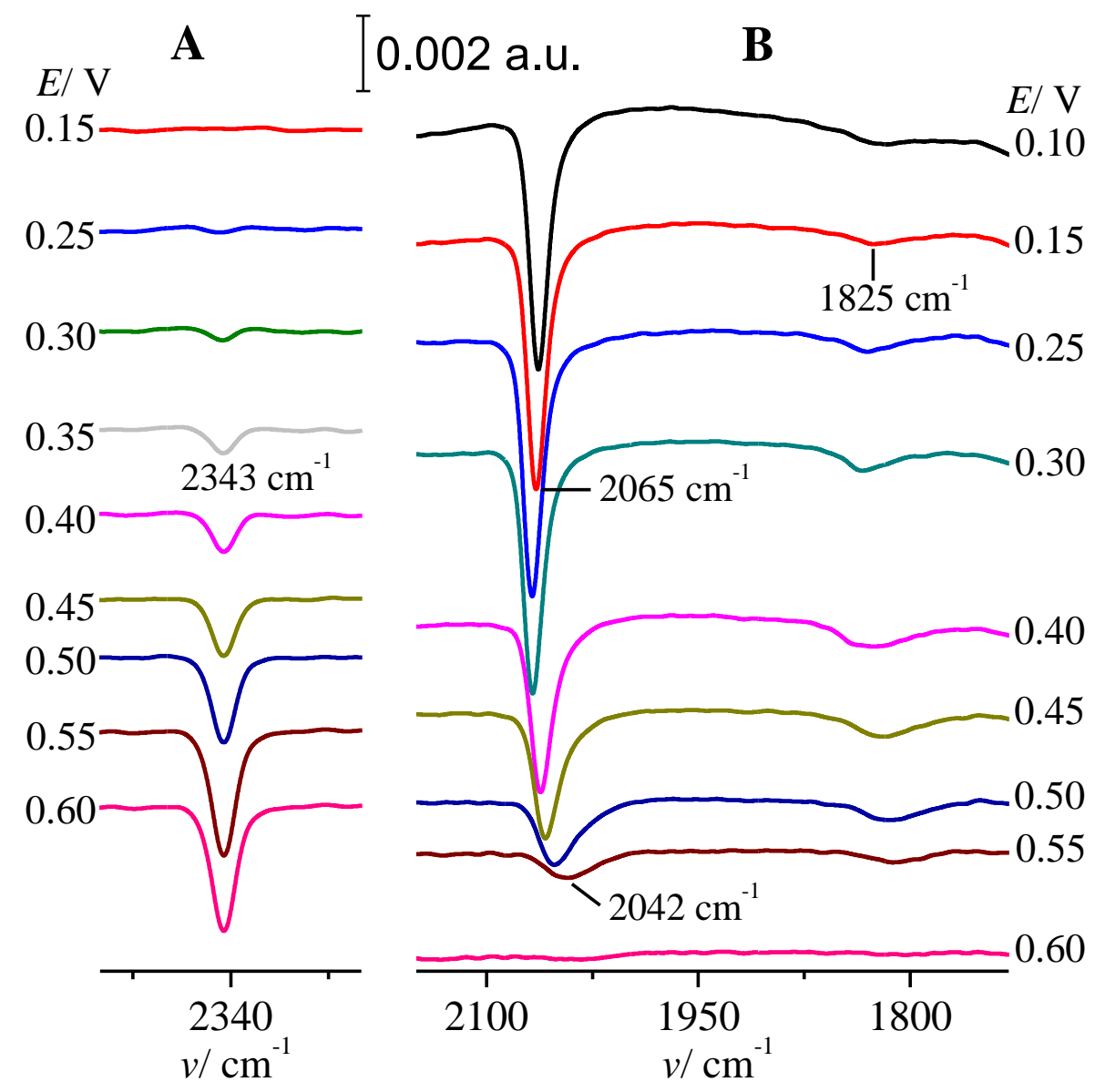

Figure 8. In situ FTIR spectra for the oxidation of a full $\mathrm{CO}$ adlayer on modified $\mathrm{Pt}(332)$ surfaces with $\theta_{\mathrm{Sn}}^{\text {Step }} \simeq 0.65$ : (Panel A) Adsorbed $\mathrm{CO}$ band frequencies, employing a reference spectrum recorded at $0.80 \mathrm{~V}$; (Panel B) Spectra for the same series displayed in Panel (A), using a different frequency range and employing a reference spectrum recorded at $0.1 \mathrm{~V}$. Some spectra are omitted for the purposes of clarity. Spectra recorded in $0.1 \mathrm{M}$ $\mathrm{HClO}_{4}$. 


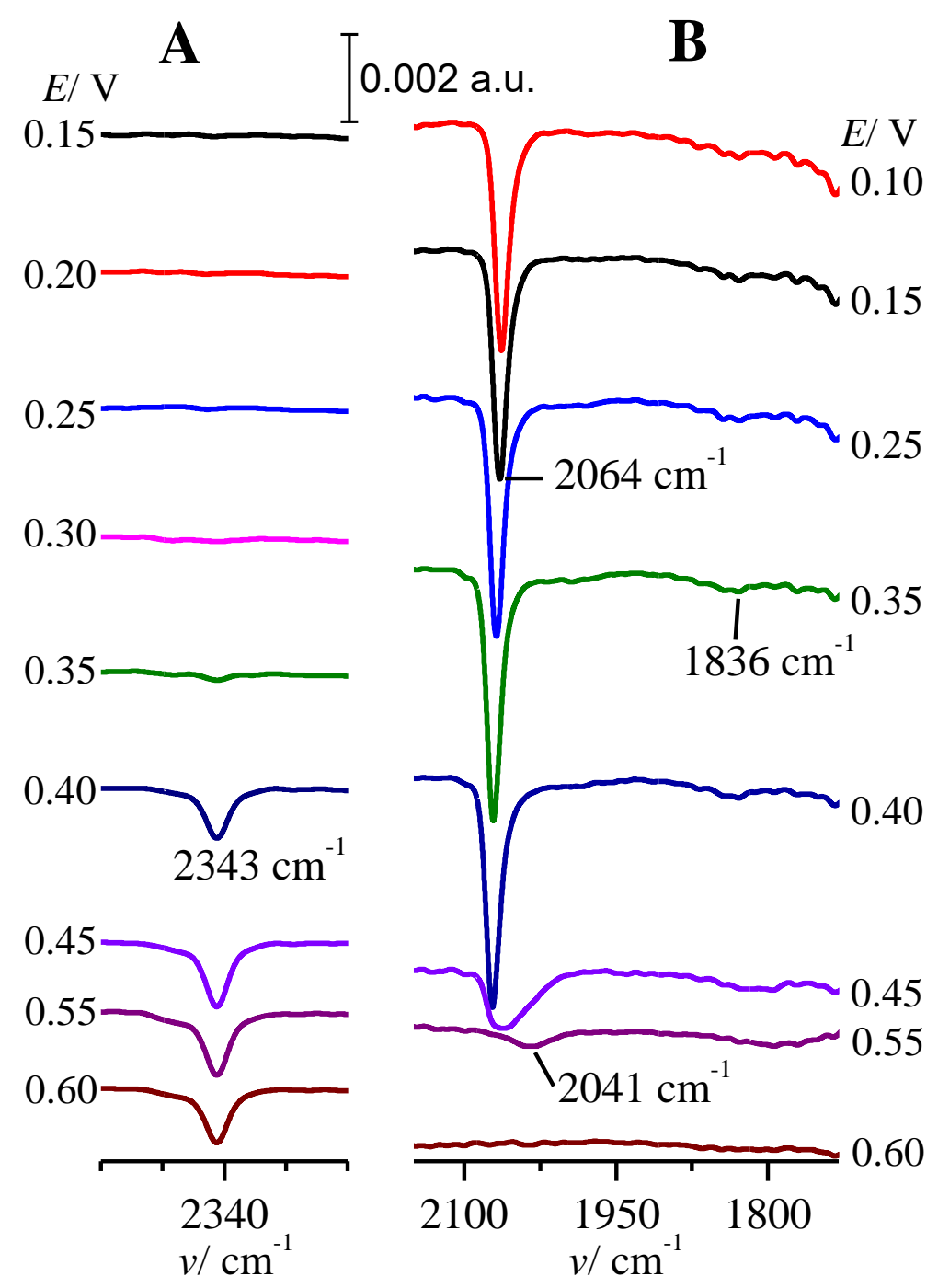

Figure 9. In situ FTIR spectra for the oxidation of a full $\mathrm{CO}$ adlayer on modified $\mathrm{Pt}(332)$ surfaces with $\theta_{\mathrm{Ru}}^{\mathrm{Step}} \simeq 0.69$ : (Panel A) Adsorbed $\mathrm{CO}$ band frequencies, employing a reference spectrum collected at $0.80 \mathrm{~V}$; (Panel B) Spectra for the same series displayed in Panel (B), using a different frequency range and employing a reference spectrum recorded at $0.1 \mathrm{~V}$. Some spectra are omitted for the purposes of clarity. Spectra recorded in $0.1 \mathrm{M} \mathrm{HClO}_{4}$. 


\section{TOC Graphic}

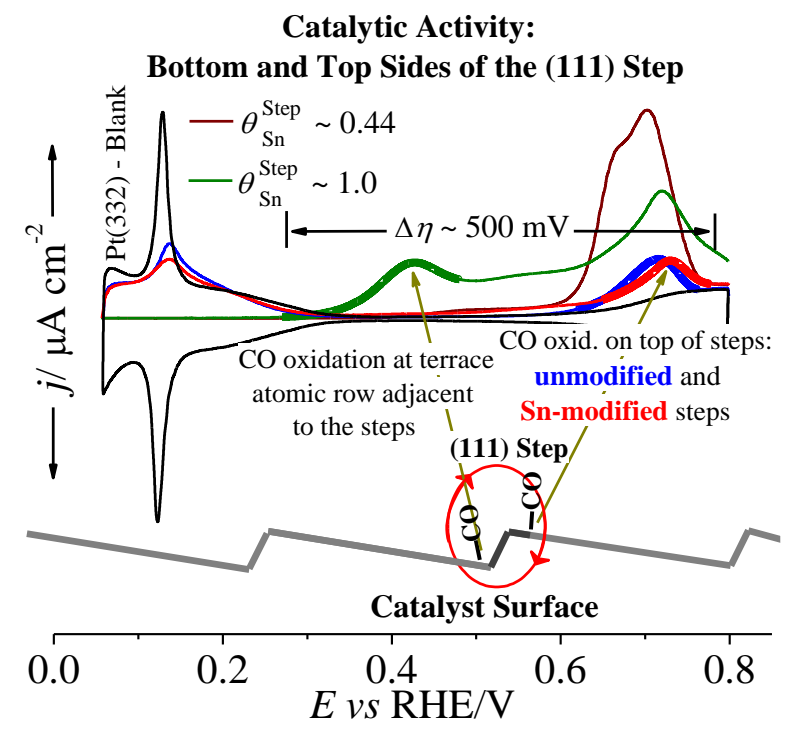

